\title{
Technical note: Consistent calculation of aquatic gross production from oxygen triple isotope measurements
}

\author{
J. Kaiser \\ School of Environmental Sciences, University of East Anglia, Norwich, NR4 7TJ, UK \\ Received: 10 April 2011 - Published in Biogeosciences Discuss.: 20 April 2011 \\ Revised: 1 July 2011 - Accepted: 6 July 2011 - Published: 11 July 2011
}

\begin{abstract}
Oxygen triple isotope measurements can be used to calculate aquatic gross oxygen production rates. Past studies have emphasised the appropriate definition of the ${ }^{17} \mathrm{O}$ excess and often used an approximation to derive production rates from the ${ }^{17} \mathrm{O}$ excess. Here, I show that the calculation can be phrased more consistently and without any approximations using the relative ${ }^{17} \mathrm{O} /{ }^{16} \mathrm{O}$ and ${ }^{18} \mathrm{O} /{ }^{16} \mathrm{O}$ isotope ratio differences (delta values) directly. I call this the "dual delta method". The ${ }^{17} \mathrm{O}$ excess is merely a mathematical construct and the derived production rate is independent of its definition, provided all calculations are performed with a consistent definition. I focus on the mixed layer, but also show how time series of triple isotope measurements below the mixed layer can be used to derive gross production.

In the calculation of mixed layer productivity, I explicitly include isotopic fractionation during gas invasion and evasion, which requires the oxygen supersaturation $s$ to be measured as well. I also suggest how bubble injection could be considered in the same mathematical framework. I distinguish between concentration steady state and isotopic steady state and show that only the latter needs to be assumed in the calculation. It is even possible to derive an estimate of the net production rate in the mixed layer that is independent of the assumption of concentration steady state.

I review measurements of the parameters required for the calculation of gross production rates and show how their systematic uncertainties as well as the use of different published calculation methods can cause large variations in the production rates for the same underlying isotope ratios. In particular, the ${ }^{17} \mathrm{O}$ excess of dissolved $\mathrm{O}_{2}$ in equilibrium with atmospheric $\mathrm{O}_{2}$ and the ${ }^{17} \mathrm{O}$ excess of photosynthetic $\mathrm{O}_{2}$ need to be re-measured. Because of these uncertainties, all calcula-
\end{abstract}

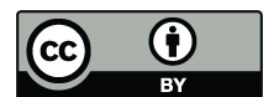

Correspondence to: J. Kaiser

(j.kaiser@uea.ac.uk) tion parameters should always be fully documented and the measured relative isotope ratio differences as well as the oxygen supersaturation should be permanently archived, so that improved measurements of the calculation parameters can be used to retrospectively improve production rates.

\section{Introduction}

Luz et al. (1999) first suggested that the triple-isotope composition of atmospheric oxygen $\left(\mathrm{O}_{2}\right)$ could be used as a tracer of biological productivity. They showed that photosynthetic $\mathrm{O}_{2}$ has a small, but measurable excess of the oxygen isotope ${ }^{17} \mathrm{O}$ with respect to atmospheric $\mathrm{O}_{2}$, after normalisation for ${ }^{18} \mathrm{O} /{ }^{16} \mathrm{O}$ isotope ratio differences. The magnitude of the ${ }^{17} \mathrm{O}$ excess $\left({ }^{17} \Delta\right)$ depends on the chosen normalisation, which is meant to account for so-called mass-dependent isotope fractionation (see Sect. 2.2).

It is clear that stratospheric isotope exchange reactions between ozone $\left(\mathrm{O}_{3}\right)$ and carbon dioxide $\left(\mathrm{CO}_{2}\right)$ are responsible for an enhanced ${ }^{17} \mathrm{O}$ isotope transfer over and above a massdependent relationship with ${ }^{18}$ O (Yung et al., 1991, 1997). Specifically, the relative ${ }^{17} \mathrm{O} /{ }^{16} \mathrm{O}$ isotope ratio difference of stratospheric $\mathrm{CO}_{2}$ to tropospheric $\mathrm{CO}_{2}$ is about 1.7 times that of the ${ }^{18} \mathrm{O} /{ }^{16} \mathrm{O}$ isotope ratio difference (Lämmerzahl et al., 2002), significantly higher than the factor of $0.516 \pm 0.015$ expected for many mass-dependent fractionation processes (Kaiser, 2008). Since $\mathrm{O}_{2}$ is the source of the oxygen atoms in the short-lived $\mathrm{O}_{3}$ molecule, this leads to corresponding ${ }^{17} \mathrm{O}$ depletion in atmospheric $\mathrm{O}_{2}$.

In the aquatic realm, the relative isotope ratio difference between atmospheric and photosynthetic oxygen can be used to calculate gross oxygen production in the mixed layer, using the gas exchange rate as a "timekeeper". Based on the simplified budget by Luz and Barkan (2000), the following

Published by Copernicus Publications on behalf of the European Geosciences Union. 
equation should hold for the ratio $(g)$ between gross $\mathrm{O}_{2}$ production $\left(P^{\prime}\right)$ and gross oxygen influx from the atmosphere $\left(k c_{\text {sat }}\right.$ ), where $k$ is the gas exchange coefficient and $c_{\text {sat }}$ the saturation concentration of $\mathrm{O}_{2}$ :

$g \equiv \frac{P^{\prime}}{k c_{\text {sat }}}=\frac{{ }^{17} \Delta-{ }^{17} \Delta_{\text {sat }}}{{ }^{17} \Delta_{\mathrm{P}}-{ }^{17} \Delta}$

${ }^{17} \Delta,{ }^{17} \Delta_{\text {sat }}$ and ${ }^{17} \Delta_{\mathrm{P}}$ refer to the ${ }^{17} \mathrm{O}$ excess of dissolved $\mathrm{O}_{2}$, dissolved $\mathrm{O}_{2}$ in equilibrium with the atmosphere and photosynthetic oxygen, respectively. The prime symbol distinguishes area-based rates $\left(P^{\prime}\right)$ from volume-based rates $(P)$. The mathematical treatment in the following is framed in terms of volume-based rates. They can be converted to areabased rates by multiplication by the depth interval for which they are calculated, e.g. the mixed-layer depth for mixedlayer production rates.

Equation (1) has been used in numerous studies to calculate gross $\mathrm{O}_{2}$ production rates (e.g. Sarma et al., 2005, 2006a, 2008; Juranek and Quay, 2005; Stanley et al., 2010; Luz and Barkan, 2005, 2009). Usually, statistical uncertainties in the measurement of ${ }^{17} \Delta$ and in the calculation of $k$ from wind speeds are cited as main contributors to the overall uncertainty in $P^{\prime}$, which may be between $15 \%$ (Stanley et al., 2010) and $40 \%$ (Quay et al., 2010; Reuer et al., 2007). To eliminate the uncertainty introduced by $k$, I focus here on the calculation of the dimensionless gross production variable $g$, which is independent of $k$.

The advantage of the oxygen triple isotope technique over ${ }^{18} \mathrm{O} /{ }^{16} \mathrm{O}$ isotope ratio measurements in determining production is that the calculated rates are independent of the respiratory isotope effect that is not well known and that would otherwise lead to significant uncertainties (Hendricks et al., 2004; Quay et al., 1993; Venkiteswaran et al., 2008). If implemented correctly, the additional information from the ${ }^{17} \mathrm{O} /{ }^{16} \mathrm{O}$ isotope ratio measurement allows elimination of the respiratory isotope effect from the production calculation.

However, different studies have used different definitions of ${ }^{17} \Delta$, without appropriately adjusting ${ }^{17} \Delta_{\text {sat }}$ and ${ }^{17} \Delta_{\mathrm{P}}$. The use of different definitions of ${ }^{17} \Delta$ means that the same measurements will give different results for $g$, causing systematic uncertainty.

Moreover, in an effort for a more rigorous derivation of Eq. (1), Hendricks et al. (2004) demonstrated that calculations of $g$ based on this equation were in error. The authors solved the exact equations iteratively, making assumptions for certain parameters and using the biological oxygen supersaturation $\Delta\left(\mathrm{O}_{2} / \mathrm{Ar}\right.$ ) (Kaiser et al., 2005) as additional constraint. Specifically, the ratio of $\Delta\left(\mathrm{O}_{2} / \mathrm{Ar}\right)$ and $g$ was assumed to be equivalent to the ratio of net $(N)$ to gross oxygen production, i.e. $f=N / P=(P-R) / P=\Delta\left(\mathrm{O}_{2} / \mathrm{Ar}\right) / g$, where $R$ stands for respiration. The same iterative approach was adopted in subsequent studies (Hendricks et al., 2005; Reuer et al., 2007; Juranek and Quay, 2010; Quay et al., 2010). Quay et al. (2010) and Juranek and Quay (2010) stated that the iterative approach gave on average $10 \%$ higher values for $g$ than Eq. (1), without exploring the underlying reasons. None of these iterative calculations considered the effect of inconsistent ${ }^{17} \Delta$ definitions and the uncertainty in the input parameters used in the calculation of $g$.

The main goal of the present study is to explore the systematic uncertainty in the calculation of $g$ from triple isotope measurements in dissolved $\mathrm{O}_{2}$. This will take into account methodological differences between past studies and the uncertainty in parameters required for the calculation. The scope of the study is limited to these aspects and neither extends to the mass-spectrometric measurement uncertainty in ${ }^{17} \Delta$, nor to the uncertainty in the gas exchange coefficient $k$, nor other systematic errors of the triple oxygen method such as the neglect of horizontal and vertical transport.

I first compare different definitions of the oxygen isotope excess ${ }^{17} \Delta$ (Sect. 2), followed by a derivation of solutions to mass balance equations for dissolved $\mathrm{O}_{2}$ and its isotopologues in systems without (Sects. 3.1 to 3.4 ) and with (Sect. 3.5) gas exchange. These equations are derived without approximations to contrast them with previously published versions. I also show that $g$ can be derived from triple isotope measurements without recourse to iterative solutions or assumptions with respect to $f$ (Sect. 4). Then I assess the systematic uncertainty due to the input parameters (Sect. 6.1). This is followed by a comparison of $g$ values calculated by different published methods from a range of synthetic data (Sect. 6.2). I will make suggestions with respect to which input parameters need to be constrained better, to reduce systematic uncertainties in the calculation of $g$. I also show how environmental data can help constrain these parameters (Sect. 6.3). All uncertainties stated here represent one standard deviation of the mean. Typesetting conventions would require all physical quantities to be in italics. However, for technical reasons this was not possible for the capital Greek delta designating the triple isotope excess ${ }^{17} \Delta$.

\section{Notation, definitions and units}

\subsection{Notation}

Isotope ratio differences ( $\delta$ values) of a sample relative to a reference are defined as follows

$\delta($ sample $/$ reference $) \equiv \frac{r(\text { sample })}{r(\text { reference })}-1$

with the solidus ( / ) separating the species of interest in numerator and denominator on the right hand side of the equation.

Using the oxygen isotopes ${ }^{17} \mathrm{O}$ and ${ }^{16} \mathrm{O}$ as an example, the isotope-amount ratio $r$ (or, shorter, the isotope ratio) is defined as

$r\left({ }^{17} \mathrm{O} /{ }^{16} \mathrm{O}\right) \equiv \frac{n\left({ }^{17} \mathrm{O}\right)}{n\left({ }^{16} \mathrm{O}\right)}$

where $n$ stands for the amount of substance. 
Accordingly, one would have to write $\delta$ (sample/reference, ${ }^{17} \mathrm{O} /{ }^{16} \mathrm{O}$ ) to fully characterise the corresponding $\delta$ value, which is impracticable for more lengthy mathematical expressions.

For clarity and simplicity, I therefore use a notation where only the minor isotope is listed as a left superscript index (just like in nuclide notation), with the species of interest given as a right subscript index, e.g. ${ }^{17} \delta_{\text {sample/reference }}$.

It is common practice to use atmospheric oxygen ("Air$\mathrm{O}_{2}$ ") as reference material for dissolved $\mathrm{O}_{2}$ in aquatic systems. The use of atmospheric oxygen as international measurement standard has been endorsed by the Commission on Isotopic Abundances and Atomic Weights (Wieser and Berglund, 2009), a commission under the Inorganic Division of the International Union of Pure and Applied Chemistry (IUPAC). When Air- $\mathrm{O}_{2}$ is the reference in the following, I will also omit it from the quantity symbol, e.g. ${ }^{17} \delta_{\text {sample }}$.

Finally, when the sample of concern is dissolved $\mathrm{O}_{2}$ in water, the corresponding index is also omitted from the quantity symbol, e.g. ${ }^{17} \delta$.

\subsection{Quantification of deviations from mass-dependent isotope ratio relationships}

As discussed by Kaiser et al. (2004), deviations from massdependent isotope ratio relationships have been defined using four functional relationships between ${ }^{17} \delta$ and ${ }^{18} \delta$.

${ }^{17} \Delta^{\dagger} \equiv{ }^{17} \delta-\kappa^{18} \delta$

(Thiemens et al., 1995)

${ }^{17} \Delta^{\ddagger} \equiv 1+{ }^{17} \delta-\left(1+{ }^{18} \delta\right)^{\lambda} \quad$ (Farquhar et al., 1998)

${ }^{17} \Delta^{*} \equiv \frac{1+{ }^{17} \delta}{\left(1+{ }^{18} \delta\right)^{\lambda}}$

(Miller et al., 2002) (6)

${ }^{17} \Delta^{\#} \equiv \ln \left(1+{ }^{17} \delta\right)-\lambda \ln \left(1+{ }^{18} \delta\right) \quad($ Angert et al., 2003) $(7)$

Superscript indices such as " $\dagger$ " have been added to distinguish between different ${ }^{17} \Delta$ definitions. I do not make a distinction between the symbols $\Delta\left({ }^{17} \mathrm{O}\right), \Delta{ }^{17} \mathrm{O}$ and ${ }^{17} \Delta$ by way of definition.

The coefficients $\kappa$ and $\lambda$ are meant to reflect the "expected" mass-dependent isotope fractionation, but strictly speaking their choice is entirely arbitrary, as these are merely definitions. Generally, $\kappa$ and $\lambda$ may be derived from empirical relationships, e.g. $\kappa=0.515$ in the case of a study on $\mathrm{N}_{2} \mathrm{O}$ (Cliff and Thiemens, 1997) or $\lambda=0.5279$ for meteoric waters (Barkan and Luz, 2007), or may be based on theoretical predictions (Young et al., 2002; Kaiser, 2008).

The designation of ${ }^{17} \Delta$ values as "isotope anomalies" may be misleading, especially when the ${ }^{17} \Delta$ values are small, because non-zero ${ }^{17} \Delta$ values might just be due to the way they were defined. More neutral terms such as ${ }^{" 17} \mathrm{O}$ excess" (Kaiser et al. 2003; Angert et al., 2004; Barkan and
Luz, 2007) and "17 O balance" (Kaiser, 2008) have been suggested. " $17 \mathrm{O}$ excess" has been adopted most widely and I will use this term here for ${ }^{17} \Delta$ values.

From a theoretical point of view, Eq. (6) is the most satisfactory because it obeys the basic isotope delta "addition theorems", e.g. $\delta_{\mathrm{A} / \mathrm{C}}=\delta_{\mathrm{A} / \mathrm{B}}+\delta_{\mathrm{B} / \mathrm{C}}+\delta_{\mathrm{A} / \mathrm{C}} \delta_{\mathrm{B} / \mathrm{C}}$. However, Eq. (4) also has merits because of its mathematical simplicity and ease of use with mass-balance and mixing calculations.

In the case of gross oxygen production calculations, Eq. (4) with $\kappa=0.521$ was used initially (Luz and Barkan, 2000; Luz et al., 1999), but following publication of the paper by Angert et al. (2003), Eq. (7) was adopted with $\lambda=0.516$ (Hendricks et al., 2004, 2005; Reuer et al., 2007; Juranek and Quay, 2005) or $\lambda=0.518$ (Sarma et al., 2005, 2006a, 2008; Stanley et al., 2010; Luz and Barkan, 2005, 2009; Quay et al., 2010; Juranek and Quay, 2010).

Per se, none of the definitions or coefficients is better or worse than others - all of them are merely mathematical constructs. However, different definitions give different ${ }^{17} \Delta$ values for the same underlying ${ }^{17} \delta{ }^{18} \delta$ pairs. Any subsequent calculations or manipulations have to bear this in mind and follow a consistent mathematical treatment. Moreover, any ${ }^{17} \Delta$ value should not be cited in isolation, i.e. not without its definition and, crucially, not without the corresponding ${ }^{18} \delta$ and/or ${ }^{17} \delta$ values. These caveats have not always been followed in the past, which, as we will see below, is partly responsible for different $g$ values obtained for the same ${ }^{17} \Delta$ values, depending on the calculation method.

For the mathematical treatment of the budget equations in the present paper I choose Eq. (4) because it simplifies the discussion. Unless required for clarity, I drop the index $\dagger$ from ${ }^{17} \Delta^{\dagger}$. I adopt $\kappa=0.5179$, based on the weighted average ratio between the ${ }^{17} \mathrm{O} /{ }^{16} \mathrm{O}$ and ${ }^{18} \mathrm{O} /{ }^{16} \mathrm{O}$ isotope fractionations during respiration (Sect. 5.1) so that

${ }^{17} \Delta \equiv{ }^{17} \delta-0.5179^{18} \delta$

If a coefficient other than 0.5179 is used, I will indicate this explicitly, e.g. ${ }^{17} \Delta(\kappa=0.521)$, corresponds to Eq. (8), but with the coefficient 0.521 .

\subsection{Units}

The ${ }^{17} \mathrm{O}$ isotope excess $\left({ }^{17} \Delta\right)$ of $\mathrm{O}_{2}$ in the atmosphere and aquatic environment is always less than $10^{-3}$. The measurement precision is usually between $1 \times 10^{-6}$ and $8 \times 10^{-6}$. ${ }^{17} \Delta$ values of $\mathrm{O}_{2}$ are therefore conveniently expressed in multiples of $10^{-6}$, for which Luz et al. (1999) used the symbol "per meg", following a similar practice adopted for gas delta values related to $\mathrm{O}_{2} / \mathrm{N}_{2}$ ratios (Keeling et al., 1998). The same symbol was also chosen by subsequent studies on oxygen triple isotopes.

However, "per meg" appears to be an awkward replacement for the symbol "ppm" (short for "parts per million"). The symbol "ppm" has traditionally been used to represent the value $10^{-6}$ and has been recognised by the SI system 
(Bureau International des Poids et Mesures (BIPM), 2006). The symbol "per meg" has no such recognition. Therefore, I will use the symbol ppm with ${ }^{17} \Delta$ values. For other $\delta$ values and isotope fractionations (designated with the symbol $\varepsilon$ ), I will use multiples of $10^{-3}$, abbreviated \%o (short for "per mill" or "parts per thousand").

\section{Budget calculations}

In the following, I give a consistent mathematical treatment of isotope budgets in increasing order of complexity, with a view to derive gross oxygen production $(P)$ and to gain an understanding of how uncertainties in the calculations parameters can affect $P$. Firstly, I discuss respiration and production on their own, then the combination of both processes, in general and under isotopic steady-state conditions, and finally explain how both processes can be combined with diffusive and bubble-mediated gas exchange.

Extensive properties (such as rates and concentrations) without an index refer to the isotope ${ }^{16} \mathrm{O}$ only. They can be related to the total value (sum over all isotopes) using the reference isotope ratios $\left(r_{\mathrm{r}}\right)$ and $\delta$ values. For example, the ${ }^{16} \mathrm{O}$ production $\left({ }^{16} \mathrm{P}=\mathrm{P}\right)$ is related to the total production $\left(P_{\text {total }}\right)$ via the following relationship:

$P={ }^{16} P=\frac{P_{\text {total }}}{1+{ }^{17} r_{\mathrm{r}}\left(1+{ }^{17} \delta_{\mathrm{P}}\right)+{ }^{18} r_{\mathrm{r}}\left(1+{ }^{18} \delta_{\mathrm{P}}\right)}$

Since ${ }^{17} r_{\mathrm{r}} \approx 0.000387,{ }^{18} r_{\mathrm{r}}=0.002053$ (Kaiser, 2008), ${ }^{17} \delta_{\mathrm{P}} \ll 1$ and ${ }^{18} \delta_{\mathrm{P}} \ll 1, P \approx P_{\text {total }}$. The correction from $P$ to $P_{\text {total }}$ is less than $0.25 \%$ and therefore negligibly small compared with other uncertainties that enter into the calculation of $P$ from triple isotope measurements.

\subsection{Respiration only}

One of the simplest budgets comprises respiration only. It has the mass balance equation

$\frac{d c}{d t}=-R$

The concentration of the major isotope ${ }^{16} \mathrm{O}$ is represented by the symbol $c$. The ${ }^{16} \mathrm{O}$ respiration $(R)$ is assumed to be of zeroth order, i.e. independent of the oxygen concentration (Bender, 1990).

The corresponding equation for ${ }^{17} \mathrm{O}$ is

$\frac{d^{17} c}{d t}=-{ }^{17} R$

The ratio between ${ }^{17} R$ and $R={ }^{16} R$ is assumed to follow the isotope distribution in dissolved $\mathrm{O}_{2}$, but modified by a respiratory isotope effect ${ }^{17} \varepsilon_{\mathrm{R}}$ (Bender, 1990):

$\frac{{ }^{17} R}{R}=\left(1+{ }^{17} \varepsilon_{\mathrm{R}}\right) \frac{{ }^{17} c}{c}$
Substituting this into Eq. (11) and using $\delta$ notation (omitting the index " 17 " from $\delta$ ) gives

$\frac{d c(1+\delta) r_{\mathrm{r}}}{d t}=-R(1+\delta) r_{\mathrm{r}}\left(1+\varepsilon_{\mathrm{R}}\right)$

The derivative is expanded and the constant $r_{\mathrm{r}}$ cancelled on both sides:

$(1+\delta) \frac{d c}{d t}+c \frac{d \delta}{d t}=-R(1+\delta)\left(1+\varepsilon_{\mathrm{R}}\right)$

Equation (10) is substituted into the preceding equation to give

$c \frac{d \delta}{d t}=-(1+\delta) R \varepsilon_{\mathrm{R}}$

and

$\frac{d \delta}{1+\delta}=-R \varepsilon_{\mathrm{R}} \frac{d t}{c}=\varepsilon_{\mathrm{R}} \frac{d c}{c}$

which can be integrated to the well-known Rayleigh fractionation equation:

$\delta=\left(1+\delta_{0}\right)\left(\frac{c}{c_{0}}\right)^{\varepsilon_{\mathrm{R}}}-1$

As pointed out by Angert et al. (2003), the resulting ${ }^{17} \Delta^{\#}$ value is

${ }^{17} \Delta^{\#}=\ln \left(1+{ }^{17} \delta_{0}\right)-\lambda \ln \left(1+{ }^{18} \delta_{0}\right)+{ }^{17} \varepsilon_{\mathrm{R}} \ln \left(c / c_{0}\right)$
$-\lambda^{18} \varepsilon_{\mathrm{R}} \ln \left(c / c_{0}\right)={ }^{17} \Delta_{0}^{\#}+\left({ }^{17} \varepsilon_{\mathrm{R}}-\lambda^{18} \varepsilon_{\mathrm{R}}\right) \ln \left(c / c_{0}\right)$

With $\lambda$ set equal to the ratio of the ${ }^{17} \mathrm{O} /{ }^{16} \mathrm{O}$ and ${ }^{18} \mathrm{O} /{ }^{16} \mathrm{O}$ isotope fractionations $\left(\gamma_{R}\right)$, i.e.

$\lambda=\gamma_{\mathrm{R}}=\frac{{ }^{17} \varepsilon_{\mathrm{R}}}{{ }^{18} \varepsilon_{\mathrm{R}}}$,

we obtain ${ }^{17} \Delta^{\#}={ }^{17} \Delta_{0}^{\#}$, i.e. ${ }^{17} \Delta^{\#}$ is not changed by respiration.

This led Angert et al. (2003) and Luz and Barkan (2005) to suggest that a ${ }^{17} \Delta$ definition following Eq. (7) with $\lambda=\gamma_{R}$ would be more appropriate than others because it removes the influence of the respiratory isotope effect on the measured ${ }^{17} \mathrm{O}$ excess. However, this assertion fails when production is included in the oxygen budget, as shown in Sects. 3.2 and 3.3.

\subsection{Production only}

An oxygen budget that includes production, but not respiration, is given by

$\frac{d c}{d t}=P$

with the corresponding isotopic relationship

$(1+\delta) \frac{d c}{d t}+c \frac{d \delta}{d t}=P\left(1+\delta_{\mathrm{P}}\right)$ 
Combining the two equations gives

$c \frac{d \delta}{d t}=P\left(\delta_{\mathrm{P}}-\delta\right) \Leftrightarrow c \frac{d \delta}{d c}=\delta_{\mathrm{P}}-\delta$

which can be integrated to

$\delta=\left(1-\frac{c_{0}}{c}\right) \delta_{\mathrm{P}}+\frac{c_{0}}{c} \delta_{0}$

In this case, there is no simple relationship between $\ln (1$ $\left.+{ }^{17} \delta\right)$ and $\ln \left(1+{ }^{18} \delta\right)$ that would single out Eq. (7) over other possible definitions of the ${ }^{17} \mathrm{O}$ excess, no matter what $\lambda$ value is chosen. However, Eq. (4) allows writing down a straightforward relationship between the corresponding ${ }^{17} \mathrm{O}$ excesses:

${ }^{17} \Delta=\left(1-\frac{c_{0}}{c}\right){ }^{17} \Delta_{\mathrm{P}}+\frac{c_{0}}{c}{ }^{17} \Delta_{0}$

This shows that as the concentration $c$ increases due to production, the influence of the initial composition $\left({ }^{17} \Delta_{0}\right)$ decreases and ${ }^{17} \Delta$ approaches ${ }^{17} \Delta_{\mathrm{P}}$ asymptotically.

\subsection{Production and respiration}

The following budget equation combines production and respiration:

$\frac{d c}{d t}=P-R$

This equation can be readily integrated to give the concentration $c$ :

$c=c_{0}+(P-R) t=c_{0}\left(1+P f t / c_{0}\right)$

with the ratio of net to gross production $f=N / P=(P-$ $R) / P$.

The corresponding equation for the minor isotope is

$(1+\delta) \frac{d c}{d t}+c \frac{d \delta}{d t}=P\left(1+\delta_{\mathrm{P}}\right)-R(1+\delta)\left(1+\varepsilon_{\mathrm{R}}\right)$

and combination of the equations for major and minor isotopes gives

$c \frac{d \delta}{d t}=P\left(\delta_{\mathrm{P}}-\delta\right)-R(1+\delta) \varepsilon_{\mathrm{R}}$

This can be integrated to

$$
\begin{aligned}
\delta & =\frac{P \delta_{\mathrm{P}}-R \varepsilon_{\mathrm{R}}}{P+R \varepsilon_{\mathrm{R}}}\left[1-\left(\frac{c}{c_{0}}\right)^{\frac{P+R \varepsilon_{\mathrm{R}}}{P-R}}\right]+\delta_{0}\left(\frac{c}{c_{0}}\right)^{\frac{P+R \varepsilon_{\mathrm{R}}}{P-R}} \\
& =\frac{P \delta_{\mathrm{P}}-R \varepsilon_{\mathrm{R}}}{P+R \varepsilon_{\mathrm{R}}}
\end{aligned}
$$

for $P \neq R$ (and therefore $f \neq 0$ ) and to

$\delta=\frac{\delta_{\mathrm{P}}-\varepsilon_{\mathrm{R}}}{1+\varepsilon_{\mathrm{R}}}\left[1-e^{\frac{P\left(1+\varepsilon_{\mathrm{R}}\right)}{c} t}\right]+\delta_{0} e^{\frac{P\left(1+\varepsilon_{\mathrm{R}}\right)}{c} t}$

for $P=R$ (and therefore $f=0$ ). There is no simple relationship between $\ln \left(1+{ }^{17} \delta\right)$ and $\ln \left(1+{ }^{18} \delta\right)$ or ${ }^{17} \delta$ and ${ }^{18} \delta$ that would single out a certain definition of ${ }^{17} \Delta$ over other possible definitions.

\subsection{Isotopic steady state between production and respiration}

The case $d \delta / d t=0$ corresponds to "isotopic steady state". Then, for any combination of $P$ and $R$, it follows from Eq. (28)

$\delta_{\mathrm{S}}=\frac{\delta_{\mathrm{P}}-(1-f) \varepsilon_{\mathrm{R}}}{1+(1-f) \varepsilon_{\mathrm{R}}}$

Isotopic steady state can be attained even when the concentrations vary (i.e. if $P \neq R$ and therefore $f \neq 0$ ). In particular, for $t \rightarrow \infty$, the $\delta$ value attained according to Eqs. (29) and (30) is equal to $\delta_{\mathrm{S}}$. However, the concentration may still increase or decrease according to Eq. (26).

The steady-state ${ }^{17} \mathrm{O}$ isotope excess could be defined with $\lambda=\ln \left[1+(1-f)^{17} \varepsilon_{\mathrm{R}}\right] / \ln \left[1+(1-f)^{18} \varepsilon_{\mathrm{R}}\right]$ so that

$$
\begin{aligned}
{ }^{17} \Delta_{\mathrm{S}}^{\#} & =\ln \left(1+{ }^{17} \delta_{\mathrm{P}}\right)-\lambda \ln \left(1+{ }^{18} \delta_{\mathrm{P}}\right)-\ln \left[1+(1-f)^{17} \varepsilon_{\mathrm{R}}\right] \\
& +\lambda \ln \left[1+(1-f){ }^{18} \varepsilon_{\mathrm{R}}\right]={ }^{17} \Delta_{\mathrm{P}}^{\#}
\end{aligned}
$$

Thus, with a choice of $\lambda$ appropriate for a certain value of $f$, it may be possible to argue that the corresponding ${ }^{17} \Delta^{\#}$ definition is preferable because the respiration isotope effect does not appear in ${ }^{17} \Delta_{\mathrm{S}}^{\#}$. Obviously, this is a misleading conclusion, since the value of $f$ is usually not known. Note that the value of ${ }^{17} \Delta_{\mathrm{P}}^{\#}$ would also depend on the value adopted for $f$ if this "tuned" value of $\lambda$ was adopted in the definition of the ${ }^{17} \mathrm{O}$ excess.

Luz and Barkan (2005) argued that the global biosphere could be considered in steady state $(P=R$, and therefore $f=0)$ and that a ${ }^{17} \Delta^{\#}$ definition with $\lambda=\ln \left(1+{ }^{17} \varepsilon_{\mathrm{R}}\right) / \ln (1$ $\left.+{ }^{18} \varepsilon_{\mathrm{R}}\right)$ would be the most suitable in this case because ${ }^{17} \Delta_{\mathrm{S}}^{\#}$ would always be equal to ${ }^{17} \Delta_{\mathrm{P}}^{\#}$, independent of the respiration fractionation. This is in contrast to their suggestion that $\lambda={ }^{17} \varepsilon_{\mathrm{R}} /{ }^{18} \varepsilon_{\mathrm{R}}$, should be chosen in other cases (see Sect. 3.1) and confirms the notion that there is no definition of the ${ }^{17} \mathrm{O}$ excess that is inherently "better" than others and that it is essentially possible to adopt any definition.

The fact that the ${ }^{17} \mathrm{O}$ excess in isotopic steady state is dependent on the $f$ ratio has important consequences for the triple isotope technique because it means that the ${ }^{17} \mathrm{O}$ excess is not only influenced by production and gas exchange, but also by respiration. This was recognised by Hendricks et al. (2004) who adopted an iterative approach to derive $g$. A simpler approach to derive $g$ is shown in Sect. 4.2.1.

To illustrate the effect of $f$ on the steadystate ${ }^{17} \mathrm{O}$ excess, I use a numerical example with $\lambda=\kappa=\gamma_{\mathrm{R}}={ }^{17} \varepsilon_{\mathrm{R}} /{ }^{18} \varepsilon_{\mathrm{R}}=0.5179,{ }^{18} \varepsilon_{\mathrm{R}}=-20 \%,{ }^{18} \delta_{\mathrm{P}}=$ $-23.323 \%$ o and ${ }^{17} \delta_{\mathrm{P}}=-11.902 \%$. This corresponds to ${ }^{17} \Delta_{\mathrm{P}}^{\#}=249 \mathrm{ppm}$. The resulting steady-state ${ }^{17} \Delta_{\mathrm{S}}^{\#}$ and ${ }^{17} \Delta_{\mathrm{S}}$ values as a function of the net to gross production ratio $f$ are shown in Fig. 1. Even without the effect of gas exchange, the ${ }^{17} \mathrm{O}$ excess varies. In particular, ${ }^{17} \Delta_{\mathrm{S}}^{\#}$ is only equal to ${ }^{17} \Delta_{\mathrm{P}}^{\#}$ for $f=1$. This means that any budget calculation involving 


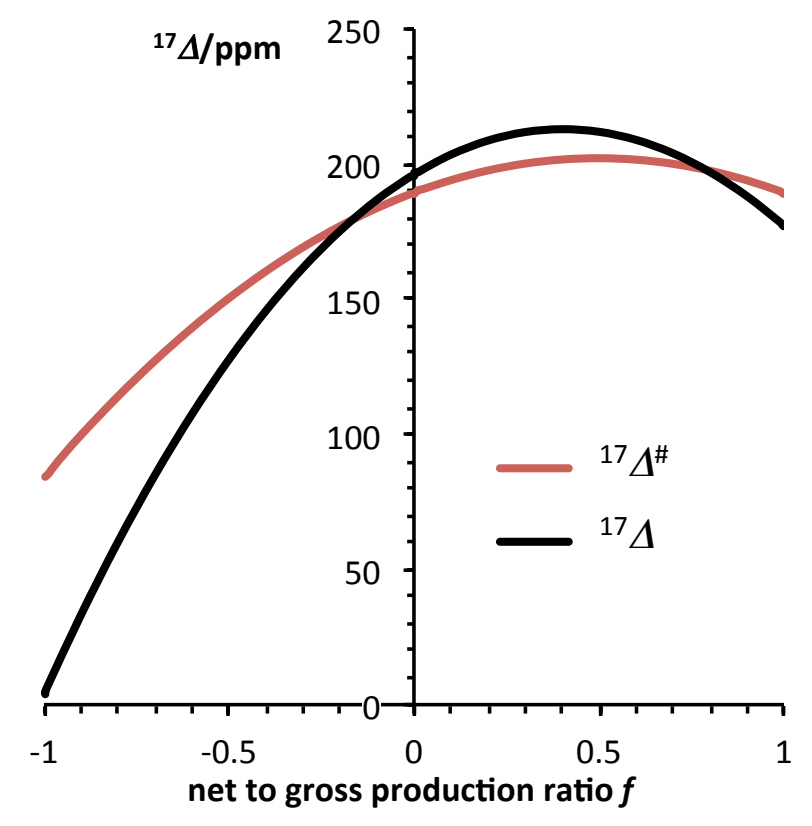

Fig. 1. Effect of the net to gross production ratio $f$ on the steady-state ${ }^{17} \mathrm{O}$ excess defined by Eq. (7), i.e. ${ }^{17} \Delta^{\#}$, and Eq. (4) i.e. ${ }^{17} \Delta$, with $\lambda=\kappa=\gamma_{\mathrm{R}}={ }^{17} \varepsilon_{\mathrm{R}} /{ }^{18} \varepsilon_{\mathrm{R}}=0.5179,{ }^{18} \varepsilon_{\mathrm{R}}=-20 \%$, ${ }^{18} \delta_{\mathrm{P}}=-23.323 \%$ and ${ }^{17} \delta_{\mathrm{P}}=-11.902 \%$ o. The steady-state $\delta$ values used to calculate the steady-state ${ }^{17} \mathrm{O}$ excess have been calculated according to Eq. (31).

triple oxygen isotopes cannot rely on the ${ }^{17} \mathrm{O}$ excess alone, but has to consider the underlying ${ }^{17} \delta$ and ${ }^{18} \delta$ values (see Sect. 5.2).

\subsection{Production, respiration and gas exchange}

I now consider production and respiration together with diffusive gas exchange; the model generally adopted for gross oxygen production calculations from triple oxygen isotopes. A similar mass balance equation was used by Hendricks et al. (2004), but the latter study did not consider the influence of isotopic fractionation during oxygen invasion from and evasion to the atmosphere. Following Luz et al. (2002), I include these fractionations here explicitly. I also show how the model could be extended to include bubble injection, which was mentioned but apparently disregarded in the gross production calculations of Stanley et al. (2010).

The mass balance equation for the major isotope (without bubble injection) is

$\frac{d c}{d t}=P-R-v_{\text {mix }}\left(c-c_{\text {sat }}\right)$

where the gas exchange frequency of the mixed layer is the ratio of gas exchange coefficient and mixed layer depth, i.e. $v_{\text {mix }}=k / z_{\text {mix }}$.
The corresponding equation for the minor isotope is

$$
\begin{gathered}
(1+\delta) \frac{d c}{d t}+c \frac{d \delta}{d t}=P\left(1+\delta_{\mathrm{P}}\right)-R(1+\delta)\left(1+\varepsilon_{\mathrm{R}}\right) \\
-v_{\text {mix }}\left[c(1+\delta)\left(1+\varepsilon_{\mathrm{E}}\right)+c_{\text {sat }}\left(1+\varepsilon_{\mathrm{I}}\right)\right]
\end{gathered}
$$

where $\varepsilon_{\mathrm{E}}$ and $\varepsilon_{\mathrm{I}}$ are the isotopic fractionations during evasion and invasion, respectively. The combination of both equations gives

$$
\begin{aligned}
c \frac{d \delta}{d t} & =P\left(\delta_{\mathrm{P}}-\delta\right)-R(1+\delta) \varepsilon_{\mathrm{R}}-v_{\text {mix }} c(1+\delta) \varepsilon_{\mathrm{E}} \\
& +v_{\text {mix }} c_{\mathrm{sat}}\left(\varepsilon_{\mathrm{I}}-\delta\right)
\end{aligned}
$$

Substituting $f=(P-R) / P, g=P /\left(v_{\text {mix }} c_{\text {sat }}\right)$ and the supersaturation $s=c / c_{\text {sat }}-1$ gives

$$
\begin{aligned}
\frac{1+s}{v_{\text {mix }}} \frac{d \delta}{d t} & =g\left(\delta_{\mathrm{P}}-\delta\right)-g(1-f)(1+\delta) \varepsilon_{\mathrm{R}} \\
& -(1+s)(1+\delta) \varepsilon_{\mathrm{E}}+\varepsilon_{\mathrm{I}}-\delta
\end{aligned}
$$

This can be re-arranged to isolate the $\delta$ value:

$\delta=\frac{g\left[\delta_{\mathrm{P}}-(1-f) \varepsilon_{\mathrm{R}}\right]-(1+s) \varepsilon_{\mathrm{E}}+\varepsilon_{\mathrm{I}}-\frac{1+s}{\nu_{\text {mix }}} \frac{d \delta}{d t}}{1+g\left[1+(1-f) \varepsilon_{\mathrm{R}}\right]+(1+s) \varepsilon_{\mathrm{E}}}$

The isotopic fractionations during evasion and invasion are related via the $\delta$ value of dissolved oxygen at saturation, $\delta_{\text {sat }}$, such that $1+\delta_{\mathrm{sat}}=\left(1+\varepsilon_{\mathrm{I}}\right) /\left(1+\varepsilon_{\mathrm{E}}\right)$. With $\varepsilon_{\mathrm{E}}=0$ we recover from Eq. (36) the corresponding equation of Hendricks et al. (2004):

$$
\frac{1+s}{v_{\text {mix }}} \frac{d \delta}{d t}=g\left(\delta_{\mathrm{P}}-\delta\right)-g(1-f)(1+\delta) \varepsilon_{\mathrm{R}}+\delta_{\text {sat }}-\delta
$$

In Sect. 4.2, I discuss how Eq. (36) can be used to derive $g$.

Bubble-mediated transfer can contribute to air-sea exchange. Usually, two bubble transfer mechanisms are distinguished: bubble injection due to complete dissolution of small bubbles and bubble exchange due to partial dissolution of larger bubbles, with bubble exchange contributing only 0 to $10 \%$ to the total bubble flux (Stanley et al., 2009). It is relatively straightforward to include bubble injection in the $\mathrm{O}_{2}$ mass balance. The smaller contribution from bubble exchange is neglected here, but could be treated in a mathematically similar way to diffusive gas exchange. The amended mass balance equation is:

$\frac{d c}{d t}=P-R-v_{\text {mix }}\left(c-c_{\text {sat }}\right)+F_{\text {inj }} \chi$

where $F_{\mathrm{inj}}$ is the air injection flux and $\chi$ is the mixing ratio of atmospheric $\mathrm{O}_{2}$. Since the $\delta$ values are expressed relative to atmospheric $\mathrm{O}_{2}$, the corresponding mass balance equation for the minor isotope (Eq. 36) has the same additional term $F_{\text {inj }} \chi$. This gives

$$
\begin{aligned}
\frac{1+s}{v_{\text {mix }}} \frac{d \delta}{d t} & =g\left(\delta_{\mathrm{P}}-\delta\right)-g(1-f)(1+\delta) \varepsilon_{\mathrm{R}} \\
& -(1+s)(1+\delta) \varepsilon_{\mathrm{E}}+\varepsilon_{\mathrm{I}}-\delta-\frac{F_{\mathrm{inj}} \chi}{v_{\text {mix }} c_{\mathrm{sat}}} \delta
\end{aligned}
$$


and

$$
\delta=\frac{g\left[\delta_{\mathrm{P}}-(1-f) \varepsilon_{\mathrm{R}}\right]-(1+s) \varepsilon_{\mathrm{E}}+\varepsilon_{\mathrm{I}}-\frac{1+s}{v_{\text {mix }}} \frac{d \delta}{d t}}{1+g\left[1+(1-f) \varepsilon_{\mathrm{R}}\right]+(1+s) \varepsilon_{\mathrm{E}}+\frac{F_{\text {inj }}}{v_{\text {mix }} c_{\mathrm{sat}}}}
$$

\section{Calculation of gross production rates}

In this section, I explain how the mass balance equations derived in Sects. 3.3 and 3.5 are used to compute gross oxygen production below and within the mixed layer.

\subsection{Production below the mixed layer}

Disregarding vertical and horizontal transport, oxygen below the mixed layer is only influenced by production and respiration (Eq. 28). By measuring temporal changes in the isotope composition of dissolved $\mathrm{O}_{2}$, it is possible to determine gross production (Luz and Barkan, 2009). The corresponding two budget equations for ${ }^{17} \mathrm{O} /{ }^{16} \mathrm{O}$ and ${ }^{18} \mathrm{O} /{ }^{16} \mathrm{O}$ isotope ratios are combined to eliminate $R$ and to compute $P$ :

$P=c \frac{\frac{1}{1+{ }^{17} \delta} \frac{d^{17} \delta}{d t}-\gamma_{\mathrm{R}} \frac{1}{1++^{18} \delta} \frac{d^{18} \delta}{d t}}{\frac{17 \delta_{\mathrm{P}}-17 \delta}{1+{ }^{17} \delta}-\gamma_{\mathrm{R}} \frac{1 \delta_{\mathrm{P}}-18 \delta}{1+{ }^{18} \delta}}$

with $\gamma_{\mathrm{R}}={ }^{17} \varepsilon_{\mathrm{R}} /{ }^{18} \varepsilon_{\mathrm{R}}$. Using ${ }^{17} \Delta={ }^{17} \delta-\kappa^{18} \delta$, this equation can also be re-written as

$$
P=c \frac{\frac{d^{17} \Delta}{d t}+\left(\frac{1+{ }^{17} \delta}{1+{ }^{18} \delta} \gamma_{\mathrm{R}}-\kappa\right) \frac{d^{18} \delta}{d t}}{{ }^{17} \Delta_{\mathrm{P}}-{ }^{17} \Delta+\left(\frac{1+{ }^{17} \delta}{1+{ }^{18} \delta} \gamma_{\mathrm{R}}-\kappa\right)\left({ }^{18} \delta_{\mathrm{P}}-{ }^{18} \delta\right)}
$$

Compare this with the approximation given by Luz and Barkan (2009) in their Eq. (5) (re-written for a single depth and corrected for two errors in the numerator - the index of their second term should be "in" - here replaced by index " 0 " - and the third term should be subtracted rather than added):

$$
\begin{aligned}
P & =\frac{c^{17} \Delta-c_{0}{ }^{17} \Delta_{0}-\frac{1}{2}\left(c-c_{0}\right)\left({ }^{17} \Delta+{ }^{17} \Delta_{0}\right)}{\Delta t\left[{ }^{17} \Delta_{\mathrm{P}}-\frac{1}{2}\left({ }^{17} \Delta+{ }^{17} \Delta_{0}\right)\right]} \\
& =\frac{\frac{1}{2}\left(c+c_{0}\right)\left({ }^{17} \Delta-{ }^{17} \Delta_{0}\right)}{\Delta t\left[{ }^{17} \Delta_{\mathrm{P}}-\frac{1}{2}\left({ }^{17} \Delta+{ }^{17} \Delta_{0}\right)\right]}
\end{aligned}
$$

which can be written in non-discretised form,

$$
P=\frac{1}{{ }^{17} \Delta_{\mathrm{P}}-{ }^{17} \Delta}\left(\frac{d c^{17} \Delta}{d t}-{ }^{17} \Delta \frac{d c}{d t}\right)=\frac{c}{{ }^{17} \Delta_{\mathrm{P}}-{ }^{17} \Delta} \frac{d^{17} \Delta}{d t}
$$

In other words, the approximate solution only agrees with the exact solution in Eq. (43) if $\kappa=\gamma_{\mathrm{R}}\left(1+{ }^{17} \delta\right) /\left(1+{ }^{18} \delta\right)$. Since ${ }^{17} \delta \ll 1$ and ${ }^{18} \delta \ll 1$, the approximate solution will often be sufficiently precise if we choose $\kappa=\gamma_{\mathrm{R}}$. However, there does not appear to be any advantage in using the approximate solution because ${ }^{17} \delta$ and ${ }^{18} \delta$ are available anyway and used to compute ${ }^{17} \Delta$. I therefore suggest choosing Eq. (42) to compute $P$ based on oxygen triple isotope measurements below the mixed layer.

\subsection{Production within the mixed layer}

In the mixed layer, we have to consider production, respiration and gas exchange in the oxygen budget (again, neglecting horizontal and vertical transport). In principle,${ }^{18} \delta$ or ${ }^{17} \delta$ alone would be sufficient to derive $g$ from Eq. (36):

$g=\frac{(1+s) \varepsilon_{\mathrm{E}}(1+\delta)-\varepsilon_{\mathrm{I}}+\delta+\frac{1+s}{v_{\text {mix }}} \frac{d \delta}{d t}}{\delta \mathrm{P}-\delta-(1-f) \varepsilon_{\mathrm{R}}(1+\delta)}$

This equation requires the temporal trend in the isotopic composition, $d \delta / d t$, to be known. Often, the temporal trend is neglected because it is small. This allows calculating $g$ based on the analysis of the oxygen triple isotope composition of a single sample. Then, we have

$g=\frac{(1+s) \varepsilon_{\mathrm{E}}(1+\delta)-\varepsilon_{\mathrm{I}}+\delta}{\delta_{\mathrm{P}}-\delta-(1-f) \varepsilon_{\mathrm{R}}(1+\delta)}$

Note that concentration steady state, i.e. $d c / d t=0$, is not required.

Most parameters $\left(\varepsilon_{\mathrm{E}}, \varepsilon_{\mathrm{I}}, \delta_{\mathrm{P}}\right)$ and variables $(s, \delta)$ can be measured with sufficient precision to calculate $g$. However, $\varepsilon_{\mathrm{R}}$ is often not sufficiently well-constrained to give precise results for $g$ (Quay et al., 1993). Moreover, $f$ has to be estimated from $s$ and $g$ via $f=s / g$ (Hendricks et al., 2004), which can introduce additional uncertainties, because the relationship $f=s / g$ is derived from assuming $d c / d t=0$ and therefore $P-R=s v_{\text {mix }} c_{\text {sat }}$, cf. Eq. (33).

\subsubsection{Direct calculation of $\mathrm{g}$ from ${ }^{17} \delta,{ }^{18} \delta$ and $\mathrm{O}_{2}$ supersaturation $s$}

Just as for production below the mixed layer, oxygen triple isotopes allow elimination of $\varepsilon_{R}$. Based on the ${ }^{17} \mathrm{O}$ and ${ }^{18} \mathrm{O}$ equivalents of Eq. (47) we obtain

$g=\frac{(1+s)\left({ }^{17} \varepsilon_{\mathrm{E}}-\gamma_{\mathrm{R}}{ }^{18} \varepsilon_{\mathrm{E}}\right)-\frac{{ }^{17} \varepsilon_{\mathrm{I}}-{ }^{17} \delta}{1+{ }^{17} \delta}+\gamma_{\mathrm{R}} \frac{{ }^{18} \varepsilon_{\mathrm{I}}{ }^{18} \delta}{1+{ }^{18} \delta}}{\frac{17 \delta_{\mathrm{P}}-{ }^{17} \delta}{1+{ }^{17} \delta}-\gamma_{\mathrm{R}} \frac{{ }^{18} \delta_{\mathrm{P}}-{ }^{18} \delta}{1+{ }^{18} \delta}}$

where $\gamma_{\mathrm{R}}={ }^{17} \varepsilon_{\mathrm{R}} /{ }^{18} \varepsilon_{\mathrm{R}}$. Eliminating $\varepsilon_{\mathrm{R}}$ has also removed the (1-f) term because it always appears as a product with $\varepsilon_{\mathrm{R}}$.

Using $\varepsilon_{\mathrm{E}}=\left(\varepsilon_{\mathrm{I}}-\delta_{\text {sat }}\right) /\left(1+\delta_{\text {sat }}\right)$, this can be written as

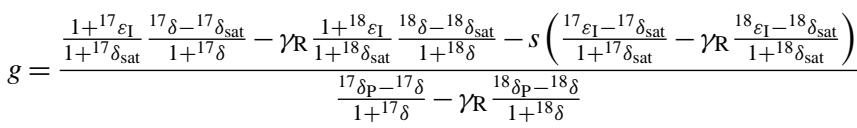

Equations (48) or (49) allow calculating $g$ based on measurements of ${ }^{17} \delta,{ }^{18} \delta$ and the $\mathrm{O}_{2}$ supersaturation $s$. For $\mathrm{O}_{2}$ concentrations near saturation $(|s| \ll 1)$, the influence of the supersaturation $s$ on the calculated value of $g$ is only small. I call this the "dual delta method" because it uses the individual ${ }^{17} \delta$ and ${ }^{18} \delta$ values rather than the triple isotope excess $\left({ }^{17} \Delta\right)$ to derive $g$. 
This calculation method also offers a route to determine $f$ that is independent of the assumption $d c / d t=0$ (concentration steady state). Rearranging Eq. (47) gives

$f=1-\frac{1}{\varepsilon_{\mathrm{R}}}\left\{\frac{\delta_{\mathrm{P}}-\delta}{1+\delta}+\frac{1}{g}\left[\frac{\varepsilon_{\mathrm{I}}-\delta}{1+\delta}-(1+s) \varepsilon_{\mathrm{E}}\right]\right\}$

Either the ${ }^{17} \delta$ or ${ }^{18} \delta$ values can be used to compute $f$; both give identical results. However, small $f$ values will be subject to the relatively large uncertainty in $\varepsilon_{\mathrm{R}}$. For example, for $f=0.1$, a $10 \%$ relative uncertainty in $\varepsilon_{\mathrm{R}}$ would translate into about $100 \%$ relative uncertainty in $f$.

To make the link to the approximate solution given by Luz and Barkan (2000) as shown in Eq. (1), I write Eq. (48) using ${ }^{17} \Delta$ notation. With ${ }^{17} \Delta={ }^{17} \delta-\kappa^{18} \delta$, I obtain

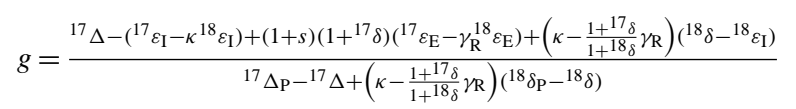

If $\kappa=\gamma_{R}\left(1+{ }^{17} \delta\right) /\left(1+{ }^{18} \delta\right),{ }^{17} \varepsilon_{\mathrm{E}}={ }^{18} \varepsilon_{\mathrm{E}}=0,{ }^{17} \varepsilon_{\mathrm{I}}={ }^{17} \delta_{\text {sat }}$ and ${ }^{18} \varepsilon_{\mathrm{I}}={ }^{18} \delta_{\text {sat }}$, we recover the approximate solution given by Luz and Barkan (2000), see Eq. (1). Since ${ }^{17} \delta \ll 1$ and ${ }^{18} \delta \ll 1$, the approximate solution will often be sufficiently precise if $\kappa=\gamma_{\mathrm{R}}$ is chosen. However, larger errors would result if ${ }^{17} \Delta^{\#}$ was chosen instead of ${ }^{17} \Delta$ with $\lambda=\gamma_{R}$ because of the non-linearity of the ${ }^{17} \Delta^{\#}$ definition (see also Sect. 6.2).

\subsubsection{Iterative calculation of $g$ from ${ }^{17} \Delta$ and $\mathrm{O}_{2}$ supersaturation $s$}

With the additional assumption of concentration steady state, i.e. $d c / d t=0$ (and therefore $s=g f$ ), it is possible to determine $g$ based on only two variables, for example, ${ }^{17} \Delta$ and $s$. This corresponds to the iterative approach used by Hendricks et al. (2004). In this case, ${ }^{18} \delta$ is calculated using the following equation derived from Eq. (37) and an initial guess for $g$ :

$\delta=\frac{g \delta_{\mathrm{P}}-(g-s) \varepsilon_{\mathrm{R}}-(1+s) \varepsilon_{\mathrm{E}}+\varepsilon_{\mathrm{I}}}{g+(g-s) \varepsilon_{\mathrm{R}}+(1+s) \varepsilon_{\mathrm{E}}+1}$

Then, ${ }^{17} \delta$ is derived from ${ }^{17} \Delta$ and ${ }^{18} \delta$ and an improved value of $g$ is calculated via Eq. (48). All steps are repeated until $g$ converges. If the assumption $d c / d t=0$ is valid, this approach gives the same result as Eq. (48). However, since the use of Eq. (48) has fewer caveats and since ${ }^{17} \delta$ and ${ }^{18} \delta$ values are available anyway, the use of Eq. (48) is preferable.

Often, it is argued that instead of the oxygen supersaturation $s$, the biological supersaturation $s_{\text {bio }}=$ $\Delta\left(\mathrm{O}_{2} / \mathrm{Ar}\right)=\left[c\left(\mathrm{O}_{2}\right) / c(\mathrm{Ar})\right] /\left[c_{\mathrm{sat}}\left(\mathrm{O}_{2}\right) / c_{\mathrm{sat}}(\mathrm{Ar})\right]-1$ should be used to calculate $g$ because it corrects $s$ for physical processes such as bubble-mediated gas transfer. While the validity of this argument was rigorously demonstrated for net production (Kaiser et al., 2005), it is not clear that it also applies for gross production. In particular, bubble injection influences the $\delta$ values in a different way than diffusive gas exchange (see Sect. 3.5), which makes the use of $s_{\text {bio }}$ inappropriate. For the present study, I will disregard the influence of bubble processes, not least because $g$ values calculated according to Eq. (48) are not very sensitive to $s$ (for $|s| \ll 1$, as commonly found in the surface ocean). In contrast, the iterative approach is affected to a larger degree by the choice between $s$ and $s_{\text {bio }}$ (see also Sect. 6.3).

\subsubsection{Non-steady state conditions - calculation of gas exchange coefficients}

For completeness, I would like to mention how the "dual delta" calculation method based on ${ }^{17} \delta$ and ${ }^{18} \delta$ can be used for non-steady state conditions. This requires the disequilibrium terms, $d \delta / d t$, to be measured. The corresponding equation to calculate $g$ is derived from Eq. (46):

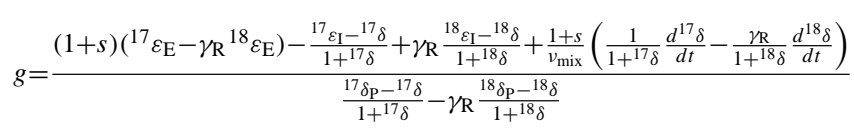

The dual delta method is also suitable for the calculation of the gas exchange coefficient $k$ based on the diurnal cycle of oxygen triple isotopes (Sarma et al., 2010). This approach assumes that $g$ is zero during the night. Measurements of ${ }^{17} \delta$ and ${ }^{18} \delta$ throughout the night can then be used to derive $k$ according to

$k=z_{\operatorname{mix}} \frac{\frac{1}{1+{ }^{17} \delta} \frac{d^{17} \delta}{d t}-\frac{\gamma_{\mathrm{R}}}{1+{ }^{18} \delta} \frac{d^{18} \delta}{d t}}{\frac{1}{1+s}\left(\frac{1 \varepsilon_{\varepsilon_{1}}{ }^{17} \delta}{1+{ }^{17} \delta}-\gamma_{\mathrm{R}} \frac{1 \varepsilon_{\varepsilon_{I}}-18 \delta}{1+{ }^{18} \delta}\right)-{ }^{17} \varepsilon_{\mathrm{E}}+\gamma_{\mathrm{R}}^{18} \varepsilon_{\mathrm{E}}}$

\section{Input parameters}

In this section I review the parameters that are required to calculate $g$ and $f$ according to Eqs. (48) and (50). Table 2 gives an overview of the parameters used and their ranges. They will be used to estimate the systematic uncertainty in $g$. I focus on parameters appropriate for the marine mixed layer because this is where the oxygen triple isotope technique has found the widest application. However, with appropriate adjustments of the parameters, the same technique can also be used for freshwater environments (Luz and Barkan, 2009).

\subsection{Respiration: ${ }^{18} \varepsilon_{\mathrm{R}},{ }^{17} \varepsilon_{\mathrm{R}}, \gamma_{\mathrm{R}}$}

The ratio $\gamma_{\mathrm{R}}={ }^{17} \varepsilon_{\mathrm{R}} /{ }^{18} \varepsilon_{\mathrm{R}}$ has been measured for individual oxygen consumption pathways, single species and community cultures (Luz and Barkan, 2005; Helman et al., 2005; Angert et al., 2003). Luz and Barkan (2005) derived a weighted average value of $\gamma_{R}=0.5179 \pm 0.0006$ from these studies and I adopt this value here. For consistency, I also set $\kappa \equiv 0.5179$ in the ${ }^{17} \Delta$ definition (Eq. 8). Some oxygen consumption reactions were found to have $\gamma_{R}$ values outside this range. For example, the Mehler reaction was shown to have $\gamma_{R}=0.526 \pm 0.002$ in isolated pea thylakoids 
and $\gamma_{\mathrm{R}}=0.497 \pm 0.004$ in a Synechocystis species, indicating different reaction mechanisms in plants and cyanobacteria (Helman et al., 2005). However, in most natural phytoplankton communities the Mehler reaction does not play a role and I do not consider it here.

For the respiration fractionation ${ }^{18} \varepsilon_{\mathrm{R}}$, a large range from $-6 \%$ for fish and human respiration to $-24 \%$ o for the alternative respiratory pathway (AOX) has been reported (Luz and Barkan, 2005; Helman et al., 2005). For the purposes of the present study, I use ${ }^{18} \varepsilon_{\mathrm{R}}=(-20 \pm 4) \%$, which is more representative of values reported for marine communities: $(-22 \pm 3) \%$ in the Southern Ocean (Hendricks et al., 2004), $(-21 \pm 2) \%$ in the Equatorial Pacific (Hendricks et al., 2005), (-22 \pm 6$) \%$ in the subarctic Pacific (Quay et al., $1993)$ and $(-20 \pm 3) \%$ o for different marine organisms (Kiddon et al., 1993).

\subsection{Photosynthesis: ${ }^{18} \delta_{\mathrm{P}},{ }^{17} \delta_{\mathrm{P}},{ }^{18} \varepsilon_{\mathrm{P}},{ }^{17} \varepsilon_{\mathrm{P}}$}

Photosynthesis involves little isotope fractionation. The isotopic composition of the produced $\mathrm{O}_{2}$ is therefore close to that of the source water. The reported ${ }^{18} \mathrm{O} /{ }^{16} \mathrm{O}$ fractionations $\left({ }^{18} \varepsilon_{\mathrm{P}}\right.$ ) are in the range -0.06 to $+0.62 \%$ o (Guy et al., 1993; Helman et al., 2005), with most measurements around $+0.50 \%$, corresponding to an isotopic enrichment of the produced $\mathrm{O}_{2}$ (inverse isotope effect). For the purposes of the present study, I assume ${ }^{18} \varepsilon_{\mathrm{P}}=(0.50 \pm 0.50) \%$ \% ${ }^{17} \varepsilon_{\mathrm{P}}$ can be inferred from the ${ }^{17} \mathrm{O}$ excess measurements of Helman et al. (2005), which gives ${ }^{17} \varepsilon_{\mathrm{P}}=(0.27 \pm 0.27) \%$, assuming that their reported ${ }^{17} \mathrm{O}$ excess is defined according to Eq. (7) with $\lambda=0.518$. The resulting ${ }^{17} \Delta$ value with respect to the source water would therefore be $(9 \pm 9) \mathrm{ppm}$. Even if Helman et al. (2005) had adopted a different ${ }^{17} \Delta$ definition than assumed here, this would most likely not lead to a significant change in ${ }^{17} \Delta$ because ${ }^{18} \varepsilon_{\mathrm{P}}$ is so small.

The ${ }^{17} \delta$ and ${ }^{18} \delta$ values of Vienna Standard Mean Ocean Water (VSMOW) have been measured as $(-11.94 \pm 0.01) \%$ o and $(-23.32 \pm 0.02) \%$ with respect to Air- $\mathrm{O}_{2}$ (Barkan and Luz, 2005). The corresponding ${ }^{17} \Delta$ value derived from the data reported by Barkan and Luz (2005) is (145 $\pm 9 \mathrm{ppm})$. Taken into account the photosynthetic isotope effect, ${ }^{18} \delta_{\mathrm{P}}$ should therefore be $(-22.83 \pm 0.50) \%$ and ${ }^{17} \delta_{\mathrm{P}}$ should be $(-11.67 \pm 0.27) \%$. This corresponds to ${ }^{17} \Delta_{\mathrm{P}}=(155 \pm$ 13) ppm. However, Luz and Barkan (2010) have shown that ocean waters are depleted in ${ }^{17} \mathrm{O}$ by $(5 \pm 1) \mathrm{ppm}$ with respect to VSMOW. The expected ${ }^{17} \Delta_{\mathrm{P}}$ value for marine photosynthesis is therefore $(150 \pm 13) \mathrm{ppm}$ or, using a frequently used definition of the ${ }^{17} \mathrm{O}$ excess, ${ }^{17} \Delta_{\mathrm{P}}^{\#}(\lambda=0.518)=(221 \pm$ 14) ppm.

A similar calculation could be done for freshwaters. For example, for a freshwater with ${ }^{18} \delta\left(\mathrm{H}_{2} \mathrm{O}\right)=-6 \%,{ }^{17} \Delta_{\mathrm{P}}$ is expected to be $(89 \pm 13) \mathrm{ppm}$, based on the meteoric water line, $\ln \left[1+{ }^{17} \delta\left(\mathrm{H}_{2} \mathrm{O}\right)\right]=(0.5280 \pm 0.0001) \ln \left[1+{ }^{18} \delta\left(\mathrm{H}_{2} \mathrm{O}\right)\right]+$ (33 \pm 3$)$ ppm (Luz and Barkan, 2010).
The value of ${ }^{17} \Delta_{\mathrm{P}}=(150 \pm 13) \mathrm{ppm}$ derived for marine photosynthetic $\mathrm{O}_{2}$ disagrees with the ${ }^{17} \mathrm{O}$ excess of $(249 \pm$ 15) ppm reported by Luz and Barkan (2000) for photosynthetic $\mathrm{O}_{2}$, which has been adopted by all subsequent studies of gross oxygen production using the triple isotope technique. To understand the disagreement, I will now look into how the value of $249 \mathrm{ppm}$ was obtained, bearing in mind that in the year 2000, none of the triple isotope studies referred to in the previous paragraph had been published yet.

Luz and Barkan (2000) measured the ${ }^{17} \Delta$ value of $\mathrm{O}_{2}$ produced by cultures of the planktonic alga Nannochloropsis and the coral Acropora, which gave on average ${ }^{17} \Delta_{\mathrm{P}}(\kappa=0.521)=(249 \pm 15) \mathrm{ppm}$. All subsequent studies using the triple isotope technique have adopted this value, even though they used different definitions of the ${ }^{17} \mathrm{O}$ excess. This leads to inconsistent results as shown in Sect. 6.2. Unfortunately, Luz and Barkan (2000) did not give the ${ }^{17} \delta$ or ${ }^{18} \delta$ values corresponding to their reported ${ }^{17} \mathrm{O}$ excess, so that it is impossible to recalculate the ${ }^{17} \mathrm{O}$ excess using other definitions, without making some assumptions.

As shown in Sect. 3.4, the steady-state $\delta_{\mathrm{S}}$ and ${ }^{17} \Delta_{\mathrm{S}}$ values depend on $f$ and the ${ }^{17} \Delta_{S}$ value measured for $f=0$ will generally not agree with ${ }^{17} \Delta_{\mathrm{P}}$. For example, for $f=0$, ${ }^{18} \delta_{\mathrm{P}}=-22.83 \%$ and ${ }^{18} \varepsilon_{\mathrm{R}}=-13.8 \%$ oreported for Acropora (Luz and Barkan, 2005), I find ${ }^{18} \delta_{\mathrm{S}}=-9.66 \%$. Based on ${ }^{17} \Delta(\kappa=0.521)=(252 \pm 5) \mathrm{ppm}($ Luz and Barkan, 2000) and $\gamma_{\mathrm{R}}=0.519$ (Luz and Barkan, 2005) reported for Acropora, this gives ${ }^{17} \Delta_{\mathrm{S}}=224 \mathrm{ppm}$ for $f=0$. In contrast, the inferred ${ }^{17} \Delta \mathrm{P}$ value for $f=1$ is $175 \mathrm{ppm}$.

The important aspect to notice here is the large difference between the steady-state ${ }^{17} \Delta_{\mathrm{S}}$ value for $f=0$ and ${ }^{17} \Delta_{\mathrm{P}}$ (for $f=1$ ), cf. Fig. $1 .{ }^{17} \Delta_{\mathrm{S}}$ value would only agree with ${ }^{17} \Delta_{\mathrm{P}}$ for an appropriately "tuned" definition of the ${ }^{17} \mathrm{O}$ excess (see Sect. 3.4). Coincidentally, in the case of Acropora, ${ }^{17} \Delta_{\mathrm{S}}^{\#}(\lambda=0.518)=236 \mathrm{ppm}$ for $f=0$ and the inferred ${ }^{17} \Delta_{\mathrm{P}}^{\#}(\lambda=0.518)$ value is $246 \mathrm{ppm}$, i.e. they are quite close to each other. The "tuned" $\lambda$ value to make them match exactly would be $\ln (1-0.519 \times 0.0138) / \ln (1-0.0138)=0.517$. In another coincidence, ${ }^{17} \Delta_{\mathrm{P}}^{\#}(\lambda=0.518)=246 \mathrm{ppm}$ is very close to ${ }^{17} \Delta(\kappa=0.521)=252 \mathrm{ppm}$ reported by Luz and Barkan (2000), which has been the basis of the average value of $(249 \pm 15)$ ppm for the photosynthetic ${ }^{17} \mathrm{O}$ excess used in all subsequent studies of triple isotope-based gross production.

What remains unexplained is the difference between the ${ }^{17} \Delta_{\mathrm{P}}^{\#}(\lambda=0.518)=(221 \pm 14) \mathrm{ppm}$ inferred at the beginning of this section and the value of $(246 \pm 5)$ ppm inferred based on the Acropora culture (a similar calculation may be possible for Nannochloropsis, but would have similar uncertainties because of the lacking ${ }^{17} \delta$ and ${ }^{18} \delta$ values). For the purposes of the present study and for consistency with other studies using the triple isotope technique, I assume ${ }^{17} \Delta_{\mathrm{P}}^{\#}$ $(\lambda=0.518)=(249 \pm 15) \mathrm{ppm}$. With ${ }^{18} \delta_{\mathrm{P}}=-22.83 \%$, this gives ${ }^{17} \Delta_{\mathrm{P}}=(180 \pm 15) \mathrm{ppm}$. However, I will also explore 
in Sect. 6.1 how the derived $g$ values would change for ${ }^{17} \Delta_{\mathrm{P}}=150 \mathrm{ppm}$.

\subsection{Gas exchange: ${ }^{18} \varepsilon_{\mathrm{I}},{ }^{17} \varepsilon_{\mathrm{I}},{ }^{18} \varepsilon_{\mathrm{E}},{ }^{17} \varepsilon_{\mathrm{E}}$}

The kinetic isotope fractionation during $\mathrm{O}_{2}$ invasion was measured as ${ }^{18} \varepsilon_{\mathrm{I}}=(-2.8 \pm 0.2) \%$ (Knox et al., 1992). I am not aware of any triple oxygen isotope studies of the corresponding ${ }^{17} \mathrm{O} /{ }^{16} \mathrm{O}$ isotope fractionation and therefore adopt ${ }^{17} \varepsilon_{\mathrm{I}}=\left(1+{ }^{18} \varepsilon_{\mathrm{I}}\right)^{\theta}-1$, with $\theta=0.516 \pm 0.015$, covering the theoretically predicted range for mass-dependent isotope effects (Kaiser, 2008).

The kinetic isotope fractionation during evasion, $\varepsilon_{\mathrm{E}}$, is calculated from $\varepsilon_{\mathrm{I}}$ and the $\delta$ value of dissolved $\mathrm{O}_{2}$ in equilibrium with the atmosphere, $\delta_{\text {sat }}$, according to $\varepsilon_{\mathrm{E}}=\left(\varepsilon_{\mathrm{I}}\right.$ $\left.-\delta_{\text {sat }}\right) /\left(1+\delta_{\text {sat }}\right) .{ }^{18} \delta_{\text {sat }}$ has been reported by Benson et al. (1979) and I use fit (2) in their Table VIII, i.e. ${ }^{18} \delta_{\text {sat }}=e^{-0.00072951+0.42696 \mathrm{~K} / T}-1$, where $T$ is the thermodynamic temperature. The fit is reported to have an uncertainty of $0.017 \%$ o for the temperature range from 0 to $60^{\circ} \mathrm{C}$.

Previous studies have neglected isotopic fractionation during evasion (i.e. $\varepsilon_{\mathrm{E}}=0$ ) and assumed that $\varepsilon_{\mathrm{I}}=\delta_{\text {sat }}$. I will consider the influence of this assumption on the calculated $g$ value in Sect. 6.1.

${ }^{17} \delta_{\text {sat }}$ is usually not reported directly, but as ${ }^{17} \mathrm{O}$ excess with respect to ${ }^{18} \delta_{\text {sat }}$. There have been a number of measurements of the ${ }^{17} \mathrm{O}$ excess that do not all agree. The published data are summarised in Table 1. After adjusting the values reported in the literature to a single ${ }^{17} \Delta$ definition following Eq. (4) with $\kappa=0.5179$, the ${ }^{17} \Delta_{\text {sat }}$ values at room temperature cluster around two values: 17 to $18 \mathrm{ppm}$ (Luz and Barkan, 2000, 2009; Sarma et al., 2006b; Juranek and Quay, 2005) and 8 to $9 \mathrm{ppm}$ (Stanley et al., 2010; Reuer et al., 2007). The measurement of $(13 \pm 5)$ ppm by Sarma et al. (2003) could be reconciled with both values, but has a high error. As already pointed out by Stanley et al. (2010) there is no consistent pattern that could explain this, such as the preparation method (bubbling versus stirring) or the water type used. The ${ }^{18} \delta_{\text {sat }}$ values were not reported in all studies, but mostly agree with those calculated using the parameterisation of Benson et al. (1979). One of the studies in the 8 to $9 \mathrm{ppm}$-cluster found an ${ }^{18} \delta_{\text {sat }}$ value that is about $0.06 \%$ o lower than the parameterisation (Reuer et al., 2007); the other study in the same cluster did not report ${ }^{18} \delta_{\text {sat }}$ (Stanley et al., 2010). Interestingly, the ${ }^{17} \Delta_{\text {sat }}$ value derived from Reuer et al. (2007) for $11^{\circ} \mathrm{C}$ (row 4a) is close to that of Luz and Barkan (2009) for $12{ }^{\circ} \mathrm{C}$ (row 5b), even though the same two studies disagree near room temperature (rows $4 \mathrm{~b}$ and $5 \mathrm{c}$ ).

In theory, bubbling should lead to slightly higher $\delta$ values. This is perhaps counter-intuitive because bubble injection adds $\mathrm{O}_{2}$ with $\delta=0$, i.e. lower than for dissolved $\mathrm{O}_{2}$ at saturation, and might therefore be expected to decrease the $\delta$ value of the $\mathrm{O}_{2}$ in the bubbled solution. Bubble exchange should have a lesser effect and is neglected here.
The reason for the enhanced $\delta$ value due to bubble injection is that bubbling leads to an enhanced $\mathrm{O}_{2}$ concentration and thus an additional evasion flux. At equilibrium, the bubble flux $F_{\text {inj }}$ has to match the diffusive gas exchange $v_{\text {mix }}(c$ $-c_{\mathrm{sat}}$ ). Using the terminology from Sect. 3.5, we require $F_{\text {inj }}=v_{\text {mix }} c_{\text {sat }} s$. The corresponding $\delta$ value at equilibrium is given by

$$
\begin{aligned}
\delta & =\frac{\varepsilon_{\mathrm{I}}-(1+s) \varepsilon_{\mathrm{E}}}{\frac{F_{\mathrm{inj}}}{v_{\text {mix }} c_{\mathrm{sat}}}+(1+s) \varepsilon_{\mathrm{E}}+1}=\frac{\varepsilon_{\mathrm{I}}-(1+s) \varepsilon_{\mathrm{E}}}{(1+s)\left(1+\varepsilon_{\mathrm{E}}\right)} \\
& =\delta_{\text {sat }}+\frac{\left(\delta_{\mathrm{sat}}-\varepsilon_{\mathrm{I}}\right) s}{(1+s)(1+\varepsilon)}
\end{aligned}
$$

Whether the corresponding ${ }^{17} \Delta$ value is higher or lower than ${ }^{17} \Delta_{\text {sat }}$ depends on $\theta$, but for $s<2 \%$, the difference should be less than $1 \mathrm{ppm}$. If $s$ were greater than $2 \%$, this would lead to an enhancement of the ${ }^{18} \delta_{\text {sat }}$ value by more than $0.07 \%$, which cannot be reconciled with the published data.

Luz and Barkan (2009) have also reported a temperature dependence of the ${ }^{17} \mathrm{O}$ excess at saturation, i.e. ${ }^{17} \Delta_{\text {sat }}^{\#}(\lambda=0.518) / \mathrm{ppm}=0.6 \vartheta /{ }^{\circ} \mathrm{C}+1.8$. At $24^{\circ} \mathrm{C}$, this gives ${ }^{17} \Delta_{\text {sat }}=16 \mathrm{ppm}$. Since a value of $16 \mathrm{ppm}$ that has been used for ${ }^{17} \Delta_{\text {sat }}$ in most previous studies, I will also adopt it here for a study of the systematic uncertainty due to the calculation method of $g$. However, I will also test a scenario with ${ }^{17} \Delta_{\text {sat }}=8 \mathrm{ppm}$.

\section{Systematic uncertainty of production within the mixed layer}

In this section I evaluate the systematic uncertainties in the calculation of mixed-layer $g$ values due to the input parameters (Sect. 6.1) and the calculation method (Sect. 6.2). The base case calculation and the evaluation of the uncertainty due to the input parameters follow Eq. (48). Since the uncertainty in $g$ depends on the values of the parameters as well as their uncertainty, I phrase this section not in terms of formal error propagation, but rather show the relative deviations from the base case, for different input parameters and calculation methods. Finally, I use a published data set of triple oxygen isotope measurements in the Southern Ocean to show how different calculation methods can affect the calculation of $g$ in practice (Sect. 6.3). I also demonstrate how concomitant isotope measurements and $\mathrm{O}_{2}$ supersaturation data can be used to check the consistency of the calculation method and to potentially improve the input parameters.

\subsection{Input parameters}

The values of the input parameters used for the base case are shown in Table 2. The ${ }^{17} \Delta$ values are shown for reference only, but are not used in the calculations. "Synthetic" ${ }^{17} \delta$ and ${ }^{18} \delta$ values are computed for a range of $g$ and $f$ values according to Eq. (37), assuming $d \delta / d t=0$ (isotopic steady 
Table 1. Triple oxygen isotope composition of dissolved $\mathrm{O}_{2}$ at saturation with atmospheric air reported in the literature. Most samples were analysed by headspace equilibration, except row $3 \mathrm{~b}$ (analysed by membrane extraction). ${ }^{18} \delta(\mathrm{B})$ is ${ }^{18} \delta$ at saturation according to Benson et al. (1979). The last column corresponds to the recalculated ${ }^{17} \mathrm{O}$ excess using the definition given by Eq. (8). Uncertainties are \pm 1 standard error. $n=$ number of measurements. A value in brackets has not been reported and was assumed. A dash (-) means that the corresponding parameter was not reported.

\begin{tabular}{|c|c|c|c|c|c|c|c|c|c|c|c|}
\hline \multirow[b]{2}{*}{ Row } & \multirow[b]{2}{*}{ Reference } & \multirow[b]{2}{*}{ Preparation } & \multirow[b]{2}{*}{ Water } & \multirow[b]{2}{*}{$\vartheta /{ }^{\circ} \mathrm{C}$} & \multicolumn{2}{|c|}{${ }^{17} \mathrm{O}$ excess (literature) } & \multirow[b]{2}{*}{$n$} & \multirow[b]{2}{*}{${ }^{18} \delta(\mathrm{B}) / \%$} & \multirow[b]{2}{*}{${ }^{18} \delta / \%$} & \multirow[b]{2}{*}{${ }^{17} \delta / \% \circ$} & \multirow[b]{2}{*}{$\begin{array}{r}{ }^{17} \Delta / \mathrm{ppm} \\
(0.5179)\end{array}$} \\
\hline & & & & & Definition & $\begin{array}{r}\text { Value/ } \\
\text { ppm }\end{array}$ & & & & & \\
\hline 2 & Juranek and Quay (2005) & stirring $^{\mathrm{a}}$ & deionised & (21) & ${ }^{17} \Delta^{\#}(0.516)$ & $18 \pm 3$ & 4 & 0.722 & $(0.722)$ & 0.391 & $17 \pm 3$ \\
\hline $3 a$ & Sarma et al. (2003) & bubbling ${ }^{\mathrm{b}}$ & distilled & 22 & ${ }^{17} \Delta(0.521)$ & $11 \pm 5$ & 10 & 0.717 & 0.691 & 0.371 & $13 \pm 5$ \\
\hline $3 b$ & Sarma et al. (2006b) & bubbling ${ }^{\mathrm{b}}$ & distilled & 24 & ${ }^{17} \Delta^{\#}(0.518)$ & $17 \pm 2$ & 10 & 0.708 & 0.717 & 0.390 & $18 \pm 2$ \\
\hline $5 \mathrm{a}$ & Luz and Barkan (2009) & bubbling & seawater & 3.5 & ${ }^{17} \Delta^{\#}(0.518)$ & $4 \pm 1$ & 5 & 0.814 & 0.811 & 0.424 & $4 \pm 1$ \\
\hline $5 b$ & Luz and Barkan (2009) & bubbling & seawater & 12.2 & ${ }^{17} \Delta^{\#}(0.518)$ & $9 \pm 1$ & 5 & 0.767 & 0.796 & 0.421 & $9 \pm 1$ \\
\hline $5 \mathrm{c}$ & Luz and Barkan (2009) & bubbling & seawater & 25.0 & ${ }^{17} \Delta^{\#}(0.518)$ & $17 \pm 2$ & 5 & 0.703 & 0.722 & 0.391 & $17 \pm 2$ \\
\hline $6 a$ & Stanley et al. (2010) & stirring & - & (21) & ${ }^{17} \Delta^{\#}(0.518)$ & $8 \pm 3$ & - & 0.722 & $(0.722)$ & 0.382 & $8 \pm 3$ \\
\hline $6 b$ & Stanley et al. (2010) & stirring & distilled & (21) & ${ }^{17} \Delta^{\#}(0.518)$ & $9 \pm 2$ & 16 & 0.722 & $(0.722)$ & 0.383 & $9 \pm 2$ \\
\hline
\end{tabular}

a According to Stanley et al. (2010).

$\mathrm{b}$ O. Abe, personal communication (2011)

Table 2. Input parameters used as base case in the calculation of $g$ (Sect. 6.1) and their uncertainties (Sect. 5). All $\delta$ values are relative to Air- $\mathrm{O}_{2}$. The ${ }^{17} \Delta$ values are defined as ${ }^{17} \Delta={ }^{17} \delta-0.5179{ }^{18} \delta$ (cf. Eq. 8) and expressed relative to Air-O $\mathrm{O}_{2}$. However, they are not needed for the calculation according to Eq. (48) and are listed for reference only. All values have been adjusted to the same decimal for clarity, irrespective of their actual uncertainty.

\begin{tabular}{|c|c|c|c|c|c|}
\hline Quantity & Symbol & Value & Unit & Uncertainty & Reference \\
\hline triple isotope fractionation ratio, respiration ${ }^{\mathrm{a}}$ & $\gamma_{\mathrm{R}}$ & 0.5179 & 1 & 0.0006 & Luz and Barkan (2005) \\
\hline${ }^{18} \mathrm{O} /{ }^{16} \mathrm{O}$ fractionation, respiration & ${ }^{11} \varepsilon_{\varepsilon_{\mathrm{R}}}$ & -20.000 & $\%$ & 4 & Kiddon et al. (1993) \\
\hline${ }^{17} \mathrm{O} /{ }^{16} \mathrm{O}$ fractionation, respiration & ${ }^{17} \varepsilon_{\mathrm{R}}$ & -10.358 & $\%$ & & calculated from ${ }^{18} \varepsilon_{\mathrm{R}}$ and $\gamma_{\mathrm{R}}$ \\
\hline isotope delta ${ }^{18} \mathrm{O} /{ }^{16} \mathrm{O}$, photosynthetic $\mathrm{O}_{2}$ & ${ }^{18} \delta_{\mathrm{P}}$ & -22.835 & $\%$ & 0.50 & see Sect. 5.2 \\
\hline isotope delta ${ }^{17} \mathrm{O} /{ }^{16} \mathrm{O}$, photosynthetic $\mathrm{O}_{2}$ & ${ }^{17} \delta_{\mathrm{P}}$ & -11.646 & $\%$ & & calculated from ${ }^{18} \delta_{\mathrm{P}}$ and ${ }^{17} \Delta_{\mathrm{P}}$ \\
\hline${ }^{17} \mathrm{O}$ excess, ${ }^{17} \mathrm{O} /{ }^{16} \mathrm{O}$, photosynthetic $\mathrm{O}_{2}$ & ${ }^{17} \Delta_{\mathrm{P}}$ & 180 & $\mathrm{ppm}$ & 15 & Luz and Barkan (2000), recalculated \\
\hline isotope delta ${ }^{18} \mathrm{O} /{ }^{16} \mathrm{O}, \mathrm{O}_{2}$ at saturation & ${ }^{18} \delta_{\text {sat }}$ & 0.707 & $\%$ & 0.017 & Benson et al. (1979) \\
\hline isotope delta ${ }^{17} \mathrm{O} /{ }^{16} \mathrm{O}, \mathrm{O}_{2}$ at saturation & ${ }^{17} \delta_{\text {sat }}$ & 0.382 & $\%$ & & calculated from ${ }^{18} \delta_{\text {sat }}$ and ${ }^{17} \Delta_{\text {sat }}$ \\
\hline${ }^{17} \mathrm{O}$ excess, $\mathrm{O}_{2}$ at saturation & ${ }^{17} \Delta_{\text {sat }}$ & 16 & ppm & 2 & Luz and Barkan (2009) \\
\hline triple isotope fractionation coefficient, $\mathrm{O}_{2}$ invasion $^{\mathrm{b}}$ & $\theta$ & 0.516 & 1 & 0.015 & estimated \\
\hline${ }^{18} \mathrm{O} /{ }^{16} \mathrm{O}$ fractionation, $\mathrm{O}_{2}$ invasion & ${ }^{18} \varepsilon_{\mathrm{I}}$ & -2.800 & $\%$ & 0.2 & Knox et al. (1992) \\
\hline${ }^{17} \mathrm{O} /{ }^{16} \mathrm{O}$ fractionation, $\mathrm{O}_{2}$ invasion & ${ }^{17} \varepsilon_{\mathrm{I}}$ & -1.446 & $\%$ & & calculated from ${ }^{18} \varepsilon_{\mathrm{I}}$ and $\theta$ \\
\hline${ }^{18} \mathrm{O} /{ }^{16} \mathrm{O}$ fractionation, $\mathrm{O}_{2}$ evasion & ${ }^{18} \varepsilon_{\mathrm{E}}$ & -3.504 & $\%$ & & calculated from ${ }^{18} \varepsilon_{\mathrm{I}}$ and ${ }^{18} \delta_{\text {sat }}$ \\
\hline${ }^{17} \mathrm{O} /{ }^{16} \mathrm{O}$ fractionation, $\mathrm{O}_{2}$ evasion & ${ }^{17} \varepsilon_{\mathrm{E}}$ & -1.827 & $\%$ & & calculated from ${ }^{17} \varepsilon_{\mathrm{I}}$ and ${ }^{17} \delta_{\text {sat }}$ \\
\hline
\end{tabular}

${ }^{\mathrm{a}} \gamma_{\mathrm{R}}={ }^{17} \varepsilon_{\mathrm{R}} /{ }^{18} \varepsilon_{\mathrm{R}}$

$\mathrm{b} \theta=\ln \left(1+{ }^{17} \varepsilon_{\mathrm{I}}\right) / \ln \left(1+{ }^{18} \varepsilon_{\mathrm{I}}\right)$.

state). The oxygen supersaturation $s$ is assumed to correspond to concentration steady state and is calculated from Eq. (33) with $d c / d t=0$, so that $s=g f$.

These synthetic ${ }^{17} \delta$ and ${ }^{18} \delta$ values are then used to derive $g$ according to Eq. (48), with one input parameter at a time increased or decreased by the corresponding uncertainty stated in Table 2. Not all parameters listed in Table 2 need to be considered: ${ }^{18} \varepsilon_{\mathrm{R}}$ and ${ }^{17} \varepsilon_{\mathrm{R}}$ have been eliminated from Eq. (48) and are therefore irrelevant. The parameters ${ }^{17} \delta_{\mathrm{P}}$, ${ }^{17} \delta_{\text {sat }},{ }^{17} \varepsilon_{\mathrm{I}},{ }^{18} \varepsilon_{\mathrm{E}}$ and ${ }^{17} \varepsilon_{\mathrm{E}}$ are calculated from other values in Table 2 and are therefore also disregarded.

This leaves the following seven parameters to test how much their associated uncertainties contribute to systematic errors in $g: \gamma_{\mathrm{R}},{ }^{18} \delta_{\mathrm{P}},{ }^{17} \Delta_{\mathrm{P}},{ }^{18} \varepsilon_{\mathrm{I}}, \theta,{ }^{18} \delta_{\text {sat }}$ and ${ }^{17} \Delta_{\text {sat. }}$ I 

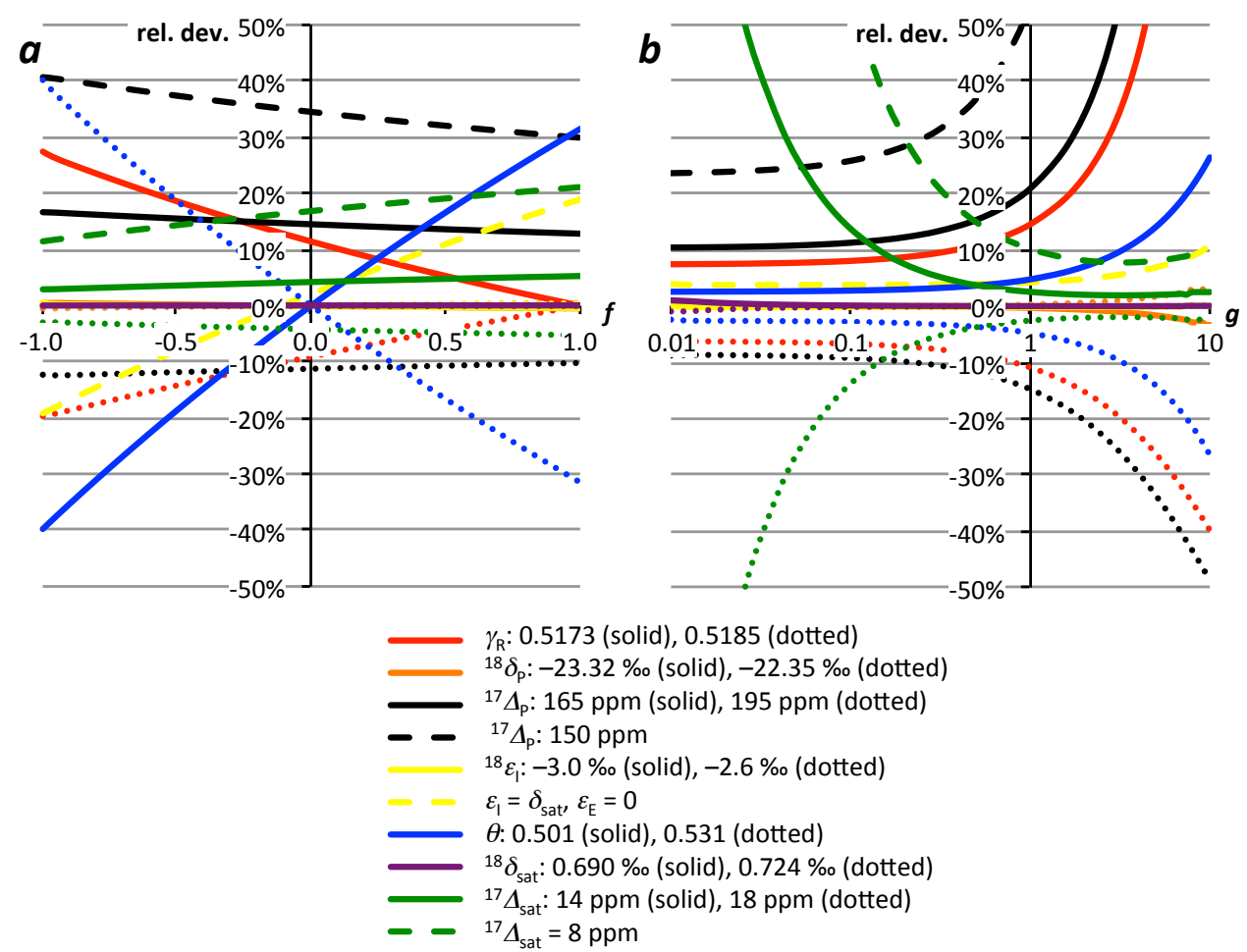

Fig. 2. Relative deviation of $g$ from the base case (see Table 2) for different parameters in Eq. (48). Panel (a) corresponds to $g=0.4$ and a range of $f$ from -1.0 to +1.0 (negative values correspond to net heterotrophy, positive value to net autotrophy). Panel (b) corresponds to $f=0.1$ and range of $g$ from 0.01 to 10 (logarithmic axis).

also include three special cases as discussed in Sects. 5.2 and 5.3. They correspond to (1) ${ }^{17} \Delta_{\mathrm{P}}=150 \mathrm{ppm}$ (based on measurements of the triple oxygen isotope composition of oceanic waters and the photosynthetic isotope fractionation), (2) $\varepsilon_{\mathrm{I}}=\delta_{\mathrm{sat}}, \varepsilon_{\mathrm{E}}=0$ (the default assumption made in previous studies) and (3) ${ }^{17} \Delta_{\text {sat }}=8 \mathrm{ppm}$ (based on measurements by Reuer et al., 2007 and Stanley et al., 2010).

To cover a large range of environmental conditions, I consider two cohorts of synthetic ${ }^{17} \delta$ and ${ }^{18} \delta$ values corresponding to (a) " $g=0.4$, varying $f$ ": a fixed $g$ value of 0.4 with $f$ varying from -1.0 to +1.0 (giving $s$ values from $-40 \%$ to $+40 \%$ and ${ }^{17} \Delta$ values from 46 to $71 \mathrm{ppm}$ ) and (b) " $f=0.1$, varying $g$ ": a fixed $f$ value of 0.1 with $g$ varying from 0.01 to 10 (giving $s$ values from $0.1 \%$ to $100 \%$ and ${ }^{17} \Delta$ values from 18 to $185 \mathrm{ppm}$ ). The range used here is larger than typically encountered for oceanic mixed layer conditions, for which $f$ is more likely to be in the range from -0.1 to +0.4 and $g$ in the range from 0.01 to 1 . However, under certain conditions, this range may be exceeded and I have therefore chosen to cover a wider range of $f$ and $g$ values. For example, recent work by Prokopenko et al. (2011) on gross oxygen production during a bloom in the coastal Bering Sea has found $f$ values up to 1 and $g$ values greater than 1 .
I express the $g$ values calculated according to different uncertainty scenarios in terms of their relative deviation from the base case $g$ values. Since the absolute deviations from the base case scale approximately with $g$, this means that the relative deviations for the " $g=0.4$, varying $f$ " are also representative for other values of $g$. The results are shown in Fig. 2.

The systematic uncertainties due to ${ }^{18} \delta_{\mathrm{P}}$ (corresponding to the ${ }^{18} \delta$ value of the source water and the photosynthetic isotope effect), ${ }^{18} \varepsilon_{\text {I }}$ and ${ }^{18} \delta_{\text {sat }}$ are negligible: the relative deviations from the base case are always less than $5 \%$ for ${ }^{18} \delta_{\mathrm{P}}$ (for an uncertainty of $\pm 0.5 \%$ ), less than $0.5 \%$ for ${ }^{18} \varepsilon_{\mathrm{I}}$ (for $\pm 0.2 \%$ ), and less than $1.5 \%$ (for $\pm 0.017 \%$ ). Only when isotopic fractionation during gas evasion is completely neglected (i.e. $\varepsilon_{\mathrm{I}}=\delta_{\text {sat }}, \varepsilon_{\mathrm{E}}=0$; the default for previous studies) do the $g$ values deviate noticeably from the base case. However, deviations greater than $10 \%$ are only reached for $|f|>0.5$ or $g>9$.

Since ${ }^{17} \Delta_{\mathrm{P}}$ and ${ }^{17} \Delta_{\text {sat }}$ enter directly into the approximated calculation of $g$ according to Eq. (1), it is not surprising that their uncertainties lead to the largest relative deviations from the base case and therefore the largest systematic uncertainty in $g$. For the " $f=0.1$, varying $g$ " cohort (Fig. 2b), the relative deviations from the base case exceed $15 \%$ for $g<0.1$ due to the $2 \mathrm{ppm}$ uncertainty in ${ }^{17} \Delta_{\text {sat }}$ and exceed 
Table 3. Comparison between different calculation methods for $g$. A dash (-) or values in brackets mean that the corresponding parameters are not used in the calculation. The "used" ${ }^{17} \mathrm{O}$ excess values are used by the different calculation methods. The "implied" ${ }^{17} \mathrm{O}$ excess values are calculated using the definitions adopted by the different calculation methods, based on the listed ${ }^{17} \delta_{\mathrm{P}},{ }^{18} \delta_{\mathrm{P}},{ }^{17} \delta_{\text {sat }}$ and ${ }^{18} \delta_{\text {sat }}$ values. Where the calculation method does not require these $\delta$ values, the values for the "best case" in Table 2 have been used for the "implied" ${ }^{17} \mathrm{O}$ excess.

\begin{tabular}{|c|c|c|c|c|c|c|c|c|c|}
\hline & & 1 & 2 & 3 & 4 & 5 & 6 & 7 & 8 \\
\hline Parameter & Unit & $\begin{array}{r}\text { Luz and } \\
\text { Barkan } \\
(2000)\end{array}$ & $\begin{array}{r}\text { Juranek } \\
\text { and Quay } \\
(2005)\end{array}$ & $\begin{array}{r}\text { Sarma et al. } \\
(2005)\end{array}$ & $\begin{array}{r}\text { Hendricks } \\
\text { et al. } \\
(2004)\end{array}$ & $\begin{array}{l}\text { Reuer } \\
\text { et al. } \\
(2007)\end{array}$ & $\begin{array}{r}\text { Juranek } \\
\text { and Quay } \\
(2010)\end{array}$ & $\begin{array}{r}\text { base case, } \\
\text { this } \\
\text { paper }\end{array}$ & $\begin{array}{r}\text { approx., } \\
\text { this } \\
\text { paper }\end{array}$ \\
\hline$g$ calculation & & Eq. (1) & Eq. (1) & Eq. (1) & iterative & iterative & iterative & Eq. (48) & Eq. (1) \\
\hline Definition & & ${ }^{17} \Delta$ (Eq. 4) & ${ }^{17} \Delta^{\#}($ Eq. 7) & ${ }^{17} \Delta^{\#}$ (Eq. 7) & ${ }^{17} \Delta^{\#}$ (Eq. 7) & ${ }^{17} \Delta^{\#}($ Eq. 7) & ${ }^{17} \Delta^{\#}($ Eq. 7) & ${ }^{17} \Delta$ (Eq. 4$)$ & ${ }^{17} \Delta$ (Eq. 4) \\
\hline$\lambda$ & 1 & - & 0.516 & 0.518 & 0.516 & 0.516 & 0.518 & - & - \\
\hline$\kappa$ & 1 & 0.521 & - & - & - & - & - & 0.5179 & 0.5179 \\
\hline$\gamma_{\mathrm{R}}$ & 1 & - & - & - & 0.5183 & 0.5185 & 0.5180 & 0.5179 & - \\
\hline${ }^{18} \varepsilon_{\mathrm{R}}$ & $\%$ & - & - & - & -18.000 & -20.000 & -20.000 & -20.000 & - \\
\hline${ }^{17} \varepsilon_{\mathrm{R}}$ & $\%$ & - & - & - & -9.329 & -10.370 & -10.360 & -10.358 & - \\
\hline${ }^{18} \delta_{\mathrm{P}}$ & $\%$ & $(-22.835)$ & $(-22.835)$ & $(-22.835)$ & -22.960 & -22.960 & -23.247 & -22.835 & $(-22.835)$ \\
\hline${ }^{17} \delta_{\mathrm{P}}$ & $\%$ & $(-11.646)$ & $(-11.646)$ & $(-11.646)$ & -11.668 & -11.668 & -11.864 & -11.646 & $(-11.646)$ \\
\hline${ }^{18} \varepsilon_{\mathrm{I}}$ & $\%$ & - & - & - & 0.707 & 0.707 & 0.707 & -2.800 & - \\
\hline${ }^{17} \varepsilon_{\mathrm{I}}$ & $\%$ & - & - & - & 0.381 & 0.373 & 0.382 & -1.446 & - \\
\hline$\theta$ & 1 & - & - & - & 0.539 & 0.527 & 0.541 & 0.516 & - \\
\hline${ }^{18} \delta_{\text {sat }}$ & $\%$ & $(0.707)$ & $(0.707)$ & $(0.707)$ & 0.707 & 0.707 & 0.707 & 0.707 & $(0.707)$ \\
\hline${ }^{17} \delta_{\text {sat }}$ & $\%$ & $(0.382)$ & $(0.382)$ & $(0.382)$ & 0.381 & 0.373 & 0.382 & 0.382 & $(0.382)$ \\
\hline${ }^{17} \Delta_{\mathrm{P}}$, used & ppm & 249 & - & - & - & - & - & 180 & 180 \\
\hline${ }^{17} \Delta_{\text {sat }}$, used & ppm & 16 & - & - & - & - & - & 16 & 16 \\
\hline${ }^{17} \Delta_{\mathrm{P}}^{\#}$, used & ppm & - & 249 & 249 & 249 & 249 & 249 & - & - \\
\hline${ }^{17} \Delta_{\text {sat }}^{\#}$, used & ppm & - & 16 & 16 & 16 & 8 & 16 & - & - \\
\hline${ }^{17} \Delta_{\mathrm{P}}$, implied & ppm & 251 & 137 & 182 & 179 & 179 & 178 & 180 & 180 \\
\hline${ }^{17} \Delta_{\text {sat }}$, implied & $\mathrm{ppm}$ & 14 & 17 & 16 & 16 & 8 & 16 & 16 & 16 \\
\hline${ }^{17} \Delta_{\mathrm{P}}^{\#}$, implied & ppm & 321 & 205 & 251 & 249 & 249 & 249 & 249 & 249 \\
\hline${ }^{17} \Delta_{\text {sat }}^{\#}$, implied & ppm & 14 & 17 & 16 & 16 & 8 & 16 & 16 & 16 \\
\hline
\end{tabular}

$15 \%$ for $g>1$ due to the $15 \mathrm{ppm}$ uncertainty in ${ }^{17} \Delta_{\mathrm{P}}$. For the " $g=0.4$, varying $f$ " (Fig. 2a) cohort, the relative deviation in the oceanographically most relevant range of $f$ from -0.1 to +0.4 is less than $15 \%$. However, for both cohorts, the relative deviations in $g$ reach $20 \%$ or more for the special cases (1) $\left({ }^{17} \Delta_{\mathrm{P}}=150 \mathrm{ppm}\right)$ and (3) $\left({ }^{17} \Delta_{\text {sat }}=8 \mathrm{ppm}\right)$.

It is perhaps surprising to see the noticeable effect of the uncertainty in $\gamma_{\mathrm{R}}$ and $\theta$ on $g$, in particular since the value of $\gamma_{\mathrm{R}}=0.5179$ is thought to have an uncertainty of only \pm 0.0006 . The relative deviations due to $\gamma_{\mathrm{R}}$ are not symmetric about the $x$-axis because $\gamma_{\mathrm{R}}$ enters Eq. (48) in both numerator and denominator. For $|f|>0.4$ or $g>1$, the relative deviations of $g$ from the base case can exceed $15 \%$; however, they stay below $15 \%$ for the oceanographically most relevant ranges of $f$ and $g$. The uncertainty in $\theta$ has a particularly noticeable effect on $g$ for the " $g=0.4$, varying $f$ " cohort (Fig. 2a). This can be explained by looking at Eq. (49), an equivalent formulation of Eq. (48). The bracketed term in the numerator of Eq. (49) can be approximated by $(\theta-$ $\left.\gamma_{\mathrm{R}}\right)^{18} \varepsilon_{\mathrm{I}}-{ }^{17} \Delta_{\text {sat }}$. Therefore, the further away from zero the $\mathrm{O}_{2}$ supersaturation $s$ is, i.e. the further away from zero $f$ is, and the larger the difference between $\theta$ and $\gamma_{\mathrm{R}}$, the more pronounced the effect on $g$.
In summary, the evaluation of the uncertainty in $g$ caused by the input parameters shows that, in principle, these parameters can be measured to within a range that does not cause systematic uncertainty $>15 \%$ for typical oceanic mixed layer conditions $(-0.1<f<+0.4,0.01<g<1)$. This means that the systematic uncertainty in $g$ would not contribute more to the overall uncertainty of gross production $P$ than the lower end of uncertainty estimates for the gas exchange coefficient $k$ (Stanley et al., 2010). However, independent measurements of ${ }^{17} \Delta_{\mathrm{P}}=150 \mathrm{ppm}$ and ${ }^{17} \Delta_{\text {sat }}=8 \mathrm{ppm}$ are not covered by the stated uncertainties in the input parameters and indicate a need for these parameters to be re-measured. Also, for more "extreme" values of $f$ and $g$, the triple oxygen isotope method is significantly impaired by the uncertainty in the input parameters of the calculation.

\subsection{Calculation method}

In this section, I evaluate the impact of different calculation methods on the derived value of $g$ for the same set of synthetic "measurements" of ${ }^{17} \delta,{ }^{18} \delta$ and oxygen supersaturation $s$ used in Sect. 6.1. None of the previously published works has used the exact input parameters I have adopted 

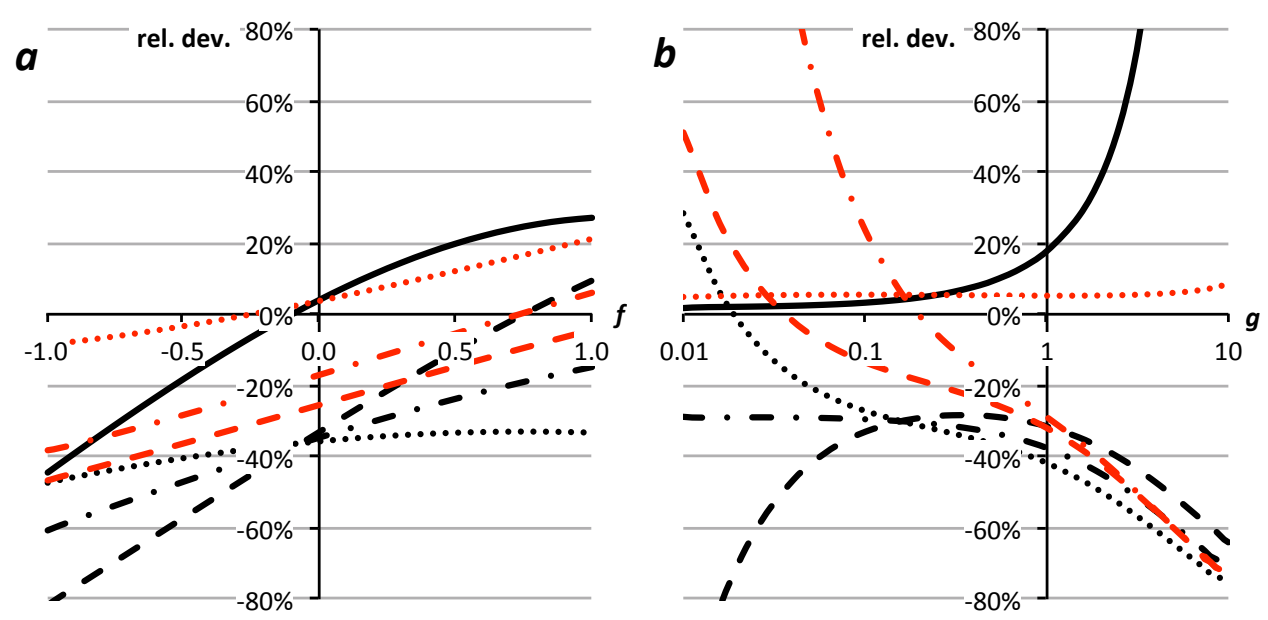

$$
\begin{aligned}
& \text { - - Luz \& Barkan (2000) } \\
& \text { - - Sarma et al. (2005) } \\
& \text { …. Juranek \& Quay (2005) } \\
& \text { — this paper, approx. } \\
& \text { - - Hendricks et al. (2004) } \\
& \text { - . Reuer et al. (2007) } \\
& \text {..... Juranek \& Quay (2010) }
\end{aligned}
$$

Fig. 3. Relative deviation of $g$ from the base case for different calculation methods (see Table 3 ). Panel (a) corresponds to $g=0.4$ and a range of $f$ from -1.0 to +1.0 (negative values correspond to net heterotrophy, positive value to net autotrophy). Panel (b) corresponds to $f=0.1$ and range of $g$ from 0.01 to 10 (logarithmic axis). Black curves correspond to calculation methods based on Eq. (1). Red curves correspond to iterative methods.

here (Table 2) although two of them are close (Juranek and Quay, 2010; Quay et al., 2010). I have compiled examples of different calculation methods from the literature in Table 3. Even though the same "measurements" were used for all calculation methods, the ${ }^{17} \mathrm{O}$ excess values differed, depending on the definition of the ${ }^{17} \mathrm{O}$ excess adopted in the particular study.

Most studies have used Eq. (1) with ${ }^{17} \Delta_{\mathrm{P}}$ (or $\left.{ }^{17} \Delta_{\mathrm{P}}^{\#}\right)=249 \mathrm{ppm}$ and ${ }^{17} \Delta_{\text {sat }}\left(\right.$ or $\left.{ }^{17} \Delta_{\text {sat }}^{\#}\right)=16 \mathrm{ppm}$, but varying coefficients in the definition of ${ }^{17} \Delta$. In none of the studies were the input parameters adjusted to the definition adopted for the ${ }^{17} \mathrm{O}$ excess. The effect of this is shown in the bottom rows of columns 1, 2, 3 and 8 in Table 3: for the same underlying ${ }^{17} \delta_{\mathrm{P}},{ }^{18} \delta_{\mathrm{P}},{ }^{17} \delta_{\text {sat }}$ and ${ }^{18} \delta_{\text {sat }}$ values, the resulting "implied" ${ }^{17} \Delta_{\mathrm{P}}$ and ${ }^{17} \Delta_{\text {sat }}$ values differ by up to $116 \mathrm{ppm}$ and 3 ppm, respectively.

A few studies have adopted an iterative approach (Sect. 4.2.2) based on the ${ }^{17} \mathrm{O}$ excess and the biological oxygen supersaturation $s_{\text {bio }}$ (columns 4 to 6 in Table 3). Different $\lambda$ values in the definitions of the ${ }^{17} \mathrm{O}$ excess and different ${ }^{18} \delta_{\mathrm{P}},{ }^{18} \varepsilon_{\mathrm{R}}$ and ${ }^{18} \delta_{\text {sat }}$ values were used (Hendricks et al., 2004; Reuer et al., 2007; Juranek and Quay, 2010). Because of this, even studies using essentially the same ${ }^{17} \Delta_{\mathrm{P}}^{\#}$ and ${ }^{17} \Delta_{\text {sat }}^{\#}$ values give different results for $g$. The distinction between $s$ and $s_{\text {bio }}$ is irrelevant for the present set of synthetic measurements. Iterative method and a calculation based on Eq. (48) therefore give the same value for $g$. However, the distinction between $s$ and $s_{\text {bio }}$ may be relevant for environmental samples, in particular if $f$ values are derived from the ratio of $g$ and $s$ in case of the iterative method.

Columns 7 and 8 of Table 3 correspond to the base case calculation according to Eq. (48) and an approximated calculation following Eq. (1), with ${ }^{17} \Delta_{\mathrm{P}}$ and ${ }^{17} \Delta_{\text {sat }}$ and the ${ }^{17} \Delta$ definition made consistent with the base case.

Figure 3 illustrates the relative difference between $g$ calculated by the different methods and the base case. For a large range of underlying $f$ and $g$ values, the $g$ values calculated according to Eq. (1) are $>25 \%$ below the base case (Luz and Barkan, 2000; Sarma et al., 2005; Juranek and Quay, 2005). This is not due to an approximation error in the derivation of Eq. (1) as illustrated by the reasonable agreement between base case calculation and approximation if ${ }^{17} \Delta_{\mathrm{P}}$ and ${ }^{17} \Delta_{\text {sat }}$ parameters consistent with the base case calculation are used ("this paper, approx."). In the case of Luz and Barkan (2000) the difference arises due to the choice of $\kappa=0.521$, which does not agree with $\gamma_{R}=0.5179 \pm 0.0006$. In the case of Sarma et al. (2005) and Juranek and Quay (2005), more suitable $\lambda$ values of 0.516 and 0.518 were chosen, which are more suitable for 
the approximated calculation of $g$ according to Eq. (1). However, the ${ }^{17} \Delta_{\mathrm{P}}^{\#}$ and ${ }^{17} \Delta_{\text {sat }}^{\#}$ values of $249 \mathrm{ppm}$ and $16 \mathrm{ppm}$ were not made consistent with this definition. Moreover, in the latter two studies, Eq. (1) was used in conjunction with a non-linear definition of the ${ }^{17} \mathrm{O}$ excess, ${ }^{17} \Delta^{\#}$. This definition was perceived to be more appropriate for the mathematical elimination of the respiration from the calculation (Luz and Barkan, 2005). However, following Sects. 3.4 and $4.2 .1,{ }^{17} \Delta$ is actually a more appropriate definition for approximated calculations of $g$ according to Eq. (1).

A better agreement with the base case is found for the iterative calculations according to Hendricks et al. (2004), Reuer et al. (2007) and Juranek and Quay (2010), with the latter calculation method giving the best agreement, mainly because the chosen $\gamma_{\mathrm{R}}$ and $\lambda$ values of 0.518 are closest to the base case value 0.5179. In case of Hendricks et al. (2004) and Reuer et al. (2007) the implied $\gamma_{R}$ values are 0.5183 and 0.5185 since these studies assume ${ }^{17} \varepsilon_{\mathrm{R}}=\left(1+{ }^{18} \varepsilon_{\mathrm{R}}\right)^{0.516}$. These $\gamma_{R}$ values contribute significantly to the deviation from the base case, especially for larger value of $g$. However, a combination of other input parameters clearly affect the derived $g$ values as well, for example the ${ }^{17} \Delta_{\text {sat }}$ value of 8 ppm adopted by Reuer et al. (2007).

\subsection{Practical example: calculation of $g$ values in the Southern Ocean}

In this section, I use a dataset of triple oxygen isotope measurements in the Southern Ocean to gauge the effect of using different calculation methods for $g$ in practice.

The data originate in the Supplementary Information to the paper by Reuer et al. (2007). From 485 concomitant measurements of ${ }^{17} \mathrm{O}$ excess (defined as ${ }^{17} \Delta^{\#}=\ln \left(1+{ }^{17} \delta\right)-$ $\left.0.516 \ln \left(1+{ }^{18} \delta\right)\right)$ and ${ }^{18} \delta$ in mixed-layer dissolved $\mathrm{O}_{2}$ samples and the biological $\mathrm{O}_{2}$ supersaturation $s_{\text {bio }}=\Delta\left(\mathrm{O}_{2} / \mathrm{Ar}\right)$, I have first calculated ${ }^{17} \delta$ and then used the dual delta method based on Eq. (48) to derive $g$, using the input parameters in Table 2 together with the temperature parameterisations of ${ }^{18} \delta_{\text {sat }}$ of Benson et al. (1979) and ${ }^{17} \Delta$ of Luz and Barkan (2009). I have assumed $s=s_{\text {bio. }}$. In Fig. 4, I have compared the result to the $g$ values based on the calculation method used in the paper by Reuer et al. (2007). A linear regression gives a slope of 1.4, indicating an even larger difference between the two calculation methods than expected from Fig. 3. This is mainly due to including the temperature dependence of ${ }^{17} \Delta$ (Luz and Barkan, 2009) as opposed to using a fixed ${ }^{17} \Delta$ value of $8 \mathrm{ppm}$ (Reuer et al., 2007). At a seawater temperature of $0{ }^{\circ} \mathrm{C}$, the temperature parameterisation gives a ${ }^{17} \Delta$ value of $2 \mathrm{ppm}$. In contrast, there is no significant difference between the iterative approach and the direct calculation of $g$ based on Eq. (48) provided the same input parameters are used; a linear regression gives a slope of $1.0027 \pm 0.0004$, a y-axis intercept of $-0.0008 \pm 0.0001$ and $R^{2}=0.9999$.

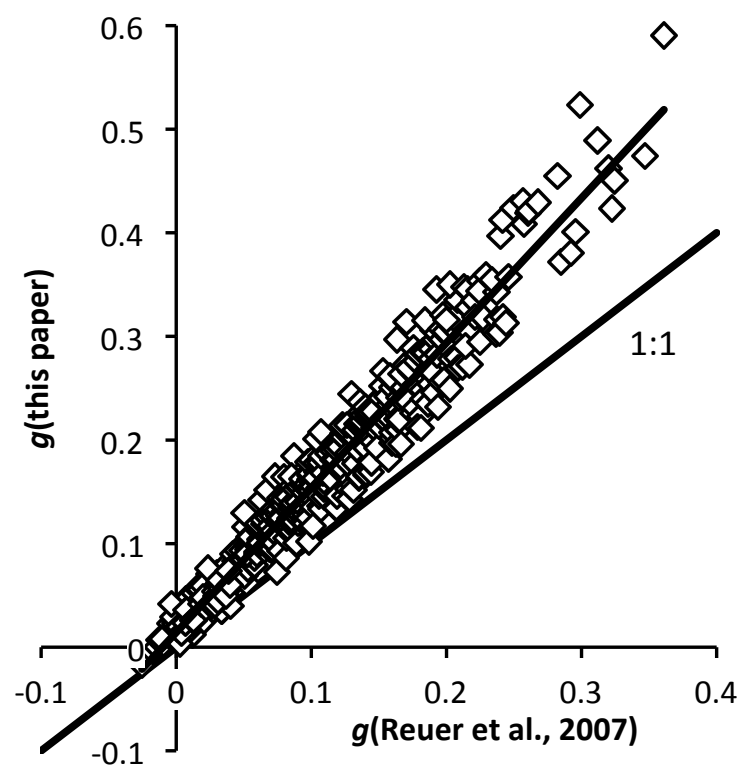

Fig. 4. Comparison between the $g$ values calculated according to columns 5 and 7 in Table 3, based on the biological oxygen supersaturation $\Delta\left(\mathrm{O}_{2} / \mathrm{Ar}\right)$ and the ${ }^{17} \delta$ and ${ }^{18} \delta$ values given in the Supplement of Reuer et al. (2007). The ${ }^{18} \delta_{\text {sat }}$ values were calculated as a function of temperature (Benson et al., 1979). For $g$ (this paper), the temperature parameterisation of ${ }^{17} \Delta_{\text {sat }}$ given by Luz and Barkan (2009) was used. For $g$ (Reuer et al., 2007), ${ }^{17} \Delta_{\text {sat }}=8 \mathrm{ppm}$ was used. Lines on the plot correspond to $g$ (this paper) $=g$ (Reuer et al., 2007) ("1:1") and a linear regression between both $g$ values, i.e. $g$ (this paper) $=(1.40 \pm 0.01) g$ (Reuer et al., 2007) $+0.014 \pm 0.002\left(R^{2}=0.95\right)$.

It was not possible to test the effect of using the $\mathrm{O}_{2}$ supersaturation $s$ instead of $s_{\text {bio }}$ because no data for $s$ were available. However, it is possible to check the internal consistency of the data set and input parameters by using Eq. (50) to calculate $f$ and to derive $s_{\text {calc }}=g f$. This check is only possible for the direct calculation method (Sect. 4.2.1) because the iterative calculation assumes $s=g f$ (Sect. 4.2.2). If there was perfect internal consistency, then $s_{\text {calc }}$ should equal $s_{\text {bio }}$.

In practice, $s_{\text {calc }}$ follows $s_{\text {bio }}$, but the agreement is not perfect (Fig. 5a). There are many reasons that could be responsible for this mismatch. For example, $f$ is much more sensitive to the input parameters ${ }^{18} \varepsilon_{\mathrm{R}},{ }^{18} \varepsilon_{\mathrm{I}},{ }^{18} \delta_{\mathrm{P}}$ etc. than $g$ and associated errors propagate to $s_{\text {calc }}$. The effect of changing ${ }^{18} \varepsilon_{\mathrm{R}}$ and ${ }^{18} \varepsilon_{\mathrm{I}}$ is illustrated in Fig. 5b-d. It appears that a stronger fractionation during gas invasion of ${ }^{18} \varepsilon_{\mathrm{I}}=-8 \%$ may lead to better agreement between $s_{\text {calc }}$ and $s_{\text {bio }}$, but this ${ }^{18} \varepsilon_{\text {I }}$ value disagrees with the measured value of $(-2.8 \pm 0.2) \%$ (Knox et al., 1992). Measurement uncertainties in ${ }^{18} \delta,{ }^{17} \delta$ and $s_{\text {bio }}$ cause scatter in the plot of $s_{\text {calc }}$ vs. $s_{\text {bio }}$ and more fundamental assumptions such as neglecting bubble transfer processes (Sect. 3.5) affect the overall correlation. In any case, it appears that there is ample scope to exploit oxygen triple isotope measurements beyond the mere calculation of gross 


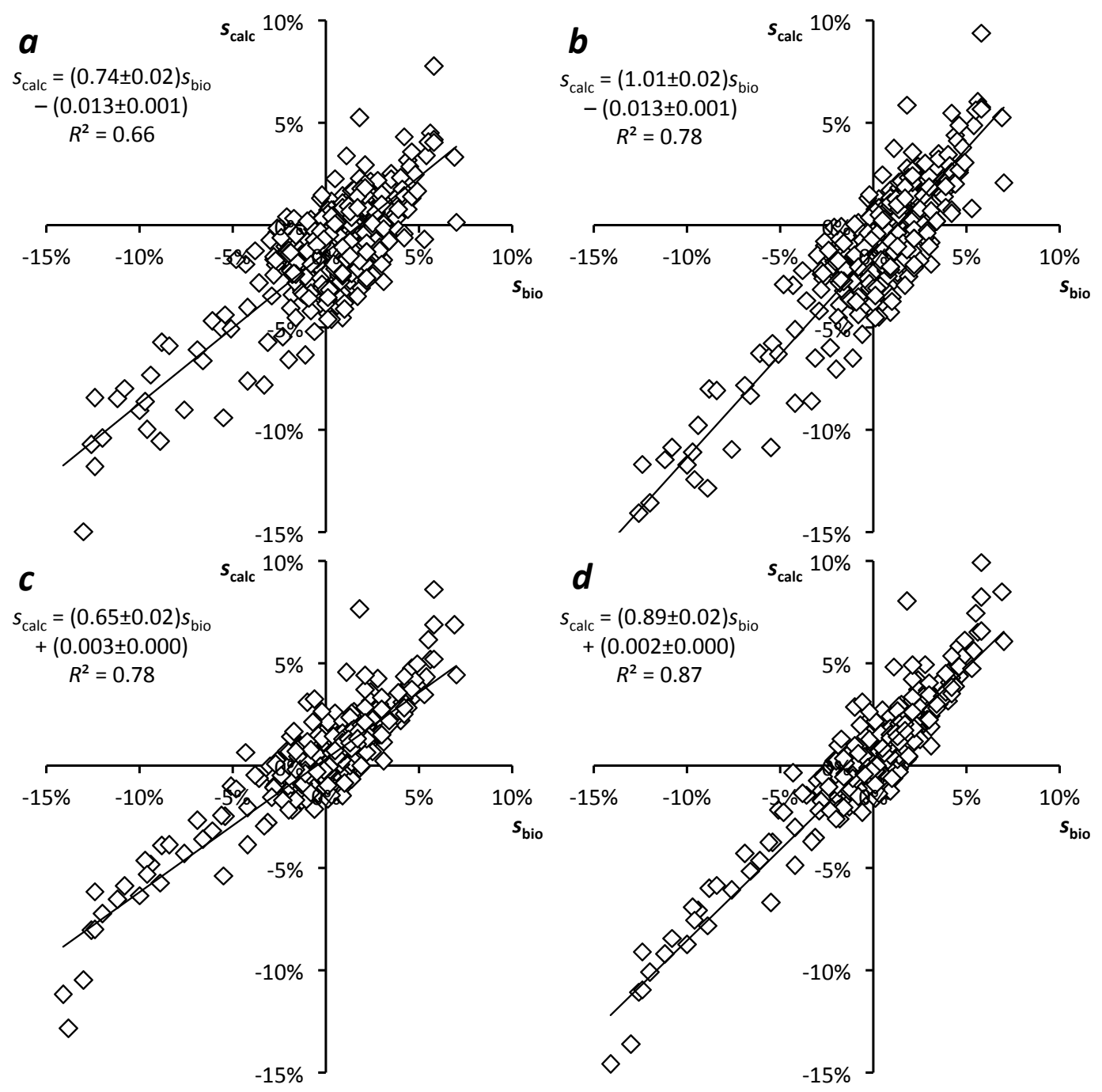

Fig. 5. Comparison between the oxygen supersaturation derived from $s_{\text {calc }}=g f$, with $g$ and $f$ calculated according to Eqs. (48) and (50), respectively, and the biological oxygen supersaturation $s_{\text {bio }}=\Delta\left(\mathrm{O}_{2} / \mathrm{Ar}\right)$ given in Reuer al. (2007). The different panels show the influence of changing different calculation parameters. Panel (a): ${ }^{18} \varepsilon_{\mathrm{I}}=-2.8 \%$ o, ${ }^{18} \varepsilon_{\mathrm{R}}=-20 \%$ o. Panel (b): ${ }^{18} \varepsilon_{\mathrm{I}}=-8.0 \%$ o, ${ }^{18} \varepsilon_{\mathrm{R}}=-20 \%$. Panel (c): ${ }^{18} \varepsilon_{\mathrm{I}}=-2.8 \%,{ }^{18} \varepsilon_{\mathrm{R}}=-22 \%$. Panel (d): ${ }^{18} \varepsilon_{\mathrm{I}}=-8.0 \%,{ }^{18} \varepsilon_{\mathrm{R}}=-22 \%$.

oxygen production rates. Clearly, in addition to allowing a more consistent calculation of $g$ (Sect. 4.2.1), the pairs of ${ }^{17} \delta$ and ${ }^{18} \delta$ values provide a wealth of additional information that cannot be subsumed by a single ${ }^{17} \mathrm{O}$ excess value that, after all, is simply a mathematical construct.

\section{Conclusions}

I have reformulated the calculation of mixed-layer gross oxygen production in terms of relative isotope ratio differences $\left({ }^{17} \delta\right.$ and ${ }^{18} \delta$ ). This so-called dual delta method is based on Eq. (48). It avoids mathematical approximations and iterative solutions and gives an explicit result in terms of a dimensionless gross oxygen production rate $g$. In addi- tion to the parameters identified previously (i.e. the ratio of ${ }^{17} \mathrm{O} /{ }^{16} \mathrm{O}$ respiration fractionation to ${ }^{18} \mathrm{O} /{ }^{16} \mathrm{O}$ respiration fractionation, $\gamma_{\mathrm{R}}={ }^{17} \varepsilon_{\mathrm{R}} /{ }^{18} \varepsilon_{\mathrm{R}}$; the ${ }^{17} \mathrm{O}$ excess for photosynthetic $\mathrm{O}_{2},{ }^{17} \Delta_{\mathrm{P}}$; and the ${ }^{17} \mathrm{O}$ excess of $\mathrm{O}_{2}$ in water saturated with atmospheric $\mathrm{O}_{2},{ }^{17} \Delta_{\text {sat }}$ ), $g$ also depends (to a lesser extent) on the ${ }^{18} \mathrm{O} /{ }^{16} \mathrm{O}$ isotope delta of photosynthetic $\mathrm{O}_{2}\left({ }^{18} \delta_{\mathrm{P}}\right)$, the ${ }^{18} \mathrm{O} /{ }^{16} \mathrm{O}$ isotope fractionation during $\mathrm{O}_{2}$ invasion $\left({ }^{18} \varepsilon_{\mathrm{I}}\right)$, the ${ }^{18} \mathrm{O} /{ }^{16} \mathrm{O}$ isotope delta of $\mathrm{O}_{2}$ in water saturated with atmospheric $\mathrm{O}_{2}\left({ }^{18} \delta_{\text {sat }}\right)$ and the triple isotope fractionation coefficient for $\mathrm{O}_{2}$ invasion $(\theta)$. A similar dual-delta approach can also be used to calculate gross production below the mixed layer, see Eq. (42).

Prokopenko et al. (2011) also found the approximated calculation of $g$ according to Eq. (1) to be deficient. If ${ }^{17} \Delta$ values are used in the calculation, adoption of a consistent 
${ }^{17} \Delta$ definition is crucial for the accuracy of the calculation. In the past, ${ }^{17} \mathrm{O}$ excess values based on different ${ }^{17} \Delta$ definitions have often been mixed indiscriminately, which leads to systematic errors. It is not important which ${ }^{17} \Delta$ definition is chosen - any single one will do, provided all calculations are performed consistently. This means essentially keeping track of at least one isotope delta (e.g. ${ }^{18} \delta$ ) in addition to ${ }^{17} \Delta$ and a clear definition of ${ }^{17} \Delta$ whenever it is used. When an approximated calculation of $g$ based on ${ }^{17} \Delta$ values and Eq. (1) is to be performed, a linear definition of ${ }^{17} \Delta$ according to Eq. (4) with $\kappa=\gamma_{\mathrm{R}}$ should be chosen to minimise errors. However, since the mass-spectrometric methods used to determine the oxygen triple isotope composition of dissolved $\mathrm{O}_{2}$, actually yield ${ }^{17} \delta$ and ${ }^{18} \delta$ rather than the derived quantity ${ }^{17} \Delta$, the dual-delta calculation method described here seems to be the preferable approach.

A marginal aspect to the ${ }^{17} \Delta$ definition is the question about the symbol for the frequently used value of $10^{-6}$. The name "per meg" has been used in the past, but is inconsistent with international metrological practice. I suggest using the internationally recognised symbol "ppm" (short for "parts per million") instead.

Table 2 gives a summary of the input parameters and their uncertainties used in the calculation of $g$. These uncertainties are based on the best single study to have measured the corresponding parameter. Using a set of synthetic ${ }^{17} \delta$ and ${ }^{18} \delta$ measurements, I have evaluated the systematic uncertainty introduced into $g$ by the different input parameters. The good news is that for the oceanographically most relevant range, the achievable measurement quality is sufficient to keep the error in $g$ at or below the minimum error estimate of $15 \%$ for the gas exchange coefficient $k$, which also enters into the calculation of the gross oxygen production according to $P=k / z_{\text {mix }} c_{\text {sat }} g$. However, in some cases, other measurements of input parameters exist that are of similar quality to the best single study, but that are not compatible with the corresponding uncertainty bands (Fig. 2). For example, the discussion about the correct ${ }^{17} \Delta_{\text {sat }}$ value is on-going (see Table 1). In case of ${ }^{17} \Delta_{\mathrm{P}}$, little experimental detail was provided with the only reported measurement (Luz and Barkan, 2000) and other measurements from the same group give a significantly lower value (Sect. 5.2). Both ${ }^{17} \Delta_{\text {sat }}$ and ${ }^{17} \Delta_{\mathrm{P}}$ should be re-measured independently.

Considerable differences can arise from using different input parameters and ${ }^{17} \mathrm{O}$ excess definitions, as shown by the evaluation of $g$ values based on different calculation methods (Table 3, Fig. 3). In the absence of an accepted recommendation on which input parameters and calculation method to use, it will be best to archive the isotope delta values themselves $\left({ }^{17} \delta\right.$ and ${ }^{18} \delta$ ), together with the oxygen supersaturation $s$ and/or the biological oxygen supersaturation $s_{\text {bio }}$, so that future methodological improvements can be applied retrospectively to existing measurements. One such improvement may be the inclusion of bubble transfer processes in the calculation of $g$, as shown for bubble injection in Eq. (41).
Another advantage of the calculation method suggested here is that it is independent of the assumption of concentration steady state (Eq. 48). Moreover, an estimate of the net to gross oxygen production ratio $f$ may be derived from isotope measurements and the oxygen supersaturation $s$ alone (Eq. 50). This may be used to check the method for internal consistency and potentially to derive improved estimates of the input parameters based on concomitant measurements of ${ }^{17} \delta,{ }^{18} \delta$ and $s$.

Acknowledgements. I would like to thank Osamu Abe and Karel Castro Morales for useful comments on an earlier version of this manuscript. This work has been supported by a Royal Society Wolfson Research Merit Award (WM052632).

Edited by: J. Middelburg

\section{References}

Angert, A., Rachmilevitch, S., Barkan, E., and Luz, B.: Effects of photorespiration, the cytochrome pathway, and the alternative pathway on the triple isotopic composition of $\mathrm{O}_{2}$, Global Biogeochem. Cy., 17, 1030, doi:10.1029/2002GB001933, 2003.

Angert, A., Cappa, C. D., and DePaolo, D. J.: Kinetic ${ }^{17} \mathrm{O}$ effects in the hydrologic cycle: Indirect evidence and implications, Geochim. Cosmochim. Ac., 68, 3487-3495, 2004.

Barkan, E. and Luz, B.: High precision measurements of ${ }^{17} \mathrm{O} /{ }^{16} \mathrm{O}$ and ${ }^{18} \mathrm{O} /{ }^{16} \mathrm{O}$ ratios in $\mathrm{H}_{2} \mathrm{O}$, Rapid Commun. Mass Sp., 19, 3737-3742, 2005.

Barkan, E. and Luz, B.: Diffusivity fractionations of $\mathrm{H}_{2}^{16} \mathrm{O} / \mathrm{H}_{2}^{17} \mathrm{O}$ and $\mathrm{H}_{2}^{16} \mathrm{O} / \mathrm{H}_{2}^{18} \mathrm{O}$ in air and their implications for isotope hydrology, Rapid Commun. Mass Sp., 21, 2999-3005, 2007.

Bender, M. L.: The $\delta^{18} \mathrm{O}$ of dissolved $\mathrm{O}_{2}$ in seawater: A unique tracer of circulation and respiration in the deep sea, J. Geophys. Res., 95, 22243-22252, 1990.

Benson, B. B., Krause, D., and Peterson, M. A.: The solubility and isotopic fractionation of gases in dilute aqueous solution, I. Oxygen, J. Solution Chem., 8, 655-690, 1979.

Cliff, S. S. and Thiemens, M. H.: The ${ }^{18} \mathrm{O} /{ }^{16} \mathrm{O}$ and ${ }^{17} \mathrm{O} /{ }^{16} \mathrm{O}$ ratios in atmospheric nitrous oxide: A mass-independent anomaly, Science, 278, 1774-1776, 1997.

Farquhar, J., Thiemens, M. H., and Jackson, T.: Atmospheresurface interactions on Mars: $\Delta^{17} \mathrm{O}$ measurements of carbonate from ALH 84001, Science, 280, 1580-1582, 1998.

Guy, R. D., Fogel, M. L., and Berry, J. A.: Photosynthetic fractionation of the stable isotopes of oxygen and carbon, Plant Physiol., 101, 37-47, 1993.

Helman, Y., Barkan, E., Eisenstadt, D., Luz, B., and Kaplan, A.: Fractionation of the three stable oxygen isotopes by oxygen-producing and oxygen-consuming reactions in photosynthetic organisms, Plant Physiol., 138, 2292-2298, doi:10.1104/pp.105.063768, 2005.

Hendricks, M. B., Bender, M. L., and Barnett, B. A.: Net and gross $\mathrm{O}_{2}$ production in the Southern Ocean from measurements of biological $\mathrm{O}_{2}$ saturation and its triple isotope composition, DeepSea Res. Pt. I, 51, 1541-1561, 2004.

Hendricks, M. B., Bender, M. L., Barnett, B. A., Strutton, P., and Chavez, F. P.: The triple oxygen isotope composition of 
dissolved $\mathrm{O}_{2}$ in the equatorial Pacific: A tracer of mixing, production, and respiration, J. Geophys. Res., 110, C12021, doi:10.1029/2004JC002735, 2005.

Juranek, L. W. and Quay, P. D.: In vitro and in situ gross primary productivity and net community production in the North Pacific Subtropical Gyre using labeled and natural abundance isotopes of dissolved $\mathrm{O}_{2}$, Global Biogeochem. Cy., 19, GB3009, doi:10.1029/2004GB002384, 2005.

Juranek, L. W. and Quay, P. D.: Basin-wide photosynthetic production rates in the subtropical and tropical $\mathrm{Pa}$ cific Ocean determined from dissolved oxygen isotope ratio measurements, Global Biogeochem. Cy., 24, GB2006, doi:10.1029/2009gb003492, 2010.

Kaiser, J.: Reformulated ${ }^{17} \mathrm{O}$ correction of mass spectrometric stable isotope measurements in carbon dioxide and a critical appraisal of historic "absolute" carbon and oxygen isotope ratios, Geochim. Cosmochim. Ac., 72, 1312-1334, doi:10.1016/j.gca.2007.12.011, 2008.

Kaiser, J., Röckmann, T., and Brenninkmeijer, C. A. M.: Complete and accurate mass-spectrometric isotope analysis of tropospheric nitrous oxide, J. Geophys. Res., 108, 4476, doi:10.1029/2003JD003613, 2003.

Kaiser, J., Röckmann, T., and Brenninkmeijer, C. A. M.: Contribution of mass-dependent fractionation to the oxygen isotope anomaly of atmospheric nitrous oxide, J. Geophys. Res., 109, D03305, doi:10.1029/2003JD004088, 2004.

Kaiser, J., Reuer, M. K., Barnett, B., and Bender, M. L.: Marine productivity estimates from continuous oxygen/argon ratio measurements by shipboard membrane inlet mass spectrometry, Geophys. Res. Lett., 32, L19605, doi:10.1029/2005GL023459, 2005.

Keeling, R. F., Stephens, B. B., Najjar, R. G., Doney, S. C., Archer, D., and Heimann, M.: Seasonal variations in the atmospheric $\mathrm{O}_{2} / \mathrm{N}_{2}$ ratio in relation to the kinetics of air-sea gas exchange, Global Biogeochem. Cy., 12, 141-163, 1998.

Kiddon, J., Bender, M. L., Orchardo, J., Caron, D. A., Goldman, J. C., and Dennett, M.: Isotopic fractionation of oxygen by respiring marine organisms, Global Biogeochem. Cy., 7, 679-694, doi:10.1029/93gb01444, 1993.

Knox, M., Quay, P. D., and Wilbur, D.: Kinetic isotopic fractionation during air-water gas transfer of $\mathrm{O}_{2}, \mathrm{~N}_{2}, \mathrm{CH}_{4}$, and $\mathrm{H}_{2}, \mathrm{~J}$. Geophys. Res., 97, 20335-20343, 1992.

Lämmerzahl, P., Röckmann, T., Brenninkmeijer, C. A. M., Krankowsky, D., and Mauersberger, K.: Oxygen isotope composition of stratospheric carbon dioxide, Geophys. Res. Lett., 29, 1582, doi:10.1029/2001GL014343, 2002.

Luz, B. and Barkan, E.: Assessment of oceanic productivity with the triple-isotope composition of dissolved oxygen, Science, 288, 2028-2031, 2000.

Luz, B. and Barkan, E.: The isotopic ratios ${ }^{17} \mathrm{O} /{ }^{16} \mathrm{O}$ and ${ }^{18} \mathrm{O} /{ }^{16} \mathrm{O}$ in molecular oxygen and their significance in biogeochemistry, Geochim. Cosmochim. Ac., 69, 1099-1110, 2005.

Luz, B. and Barkan, E.: Net and gross oxygen production from $\mathrm{O}_{2} / \mathrm{Ar},{ }^{17} \mathrm{O} /{ }^{16} \mathrm{O}$ and ${ }^{18} \mathrm{O} /{ }^{16} \mathrm{O}$ ratios, Aquat. Microb. Ecol., 56, 133-145, 2009.

Luz, B. and Barkan, E.: Variations of $17 \mathrm{O} / 16 \mathrm{O}$ and $18 \mathrm{O} / 16 \mathrm{O}$ in meteoric waters, Geochim. Cosmochim. Ac., 74, 6276-6286, doi:10.1016/j.gca.2010.08.016, 2010.

Luz, B., Barkan, E., Bender, M. L., Thiemens, M. H., and Boering, K. A.: Triple-isotope composition of atmospheric oxygen as a tracer of biosphere productivity, Nature, 400, 547-550, 1999.

Luz, B., Barkan, E., Sagi, Y., and Yacobi, Y. Z.: Evaluation of community respiratory mechanisms with oxygen isotopes: A case study in Lake Kinneret, Limnol. Oceanogr., 47, 33-42, 2002.

Miller, M. F., Franchi, I. A., Thiemens, M. H., Jackson, T. L., Brack, A., Kurat, G., and Pillinger, C. T.: Mass-independent fractionation of oxygen isotopes during thermal decomposition of carbonates, P. Natl. Acad. Sci., 99, 10988-10993, doi:10.1073/pnas.172378499, 2002.

Prokopenko, M. G., Pauluis, O. M., Granger, J., and Yeung, L. Y.: Exact evaluation of gross photosynthetic production from the oxygen triple-isotope composition of $\mathrm{O}_{2}$ : implications for the net-to-gross primary production ratios, Geophys. Res. Lett., doi:10.1029/2011GL047652, in press, 2011.

Quay, P. D., Emerson, S., Wilbur, D. O., and Stump, C.: The $\delta^{18} \mathrm{O}$ of dissolved oxygen in the surface waters of the subarctic Pacific: A tracer of biological productivity, J. Geophys. Res., 98, 84478458, 1993.

Quay, P. D., Peacock, C., Björkman, K., and Karl, D. M.: Measuring primary production rates in the ocean: Enigmatic results between incubation and non-incubation methods at Station ALOHA, Global Biogeochem. Cy., 24, GB3014, doi:10.1029/2009gb003665, 2010.

Reuer, M. K., Barnett, B. A., Bender, M. L., Falkowski, P. G., and Hendricks, M. B.: New estimates of Southern Ocean biological production rates from $\mathrm{O}_{2} / \mathrm{Ar}$ ratios and the triple isotope composition of $\mathrm{O}_{2}$, Deep-Sea Res. Pt. I, 54, 951-974, 2007.

Sarma, V., Abe, O., Hashimoto, S., Hinuma, A., and Saino, T.: Seasonal variations in triple oxygen isotopes and gross oxygen production in the Sagami Bay, central Japan, Limnol. Oceanogr., 50, 544-552, 2005.

Sarma, V. V. S. S., Abe, O., and Saino, T.: Chromatographic separation of nitrogen, argon, and oxygen in dissolved air for determination of triple oxygen isotopes by dual-inlet mass spectrometry, Anal. Chem., 75, 4913-4917, doi:10.1021/ac034314r, 2003.

Sarma, V. V. S. S., Abe, O., Hinuma, A., and Saino, T.: Short-term variation of triple oxygen isotopes and gross oxygen production in the Sagami Bay, central Japan, Limnol. Oceanogr., 51, 14321442, 2006a.

Sarma, V. V. S. S., Abe, O., Yoshida, N., and Saino, T.: Continuous shipboard sampling system for determination of triple oxygen isotopes and $\mathrm{O}_{2} / \mathrm{Ar}$ ratio by dual-inlet mass spectrometry, Rapid Commun. Mass Sp., 20, 3503-3508, 2006 b.

Sarma, V. V. S. S., Abe, O., and Saino, T.: Spatial variations in time-integrated plankton metabolic rates in Sagami Bay using triple oxygen isotopes and $\mathrm{O}_{2}$ :Ar ratios, Limnol. Oceanogr., 53, 1776-1783, 2008.

Sarma, V. V. S. S., Abe, O., Honda, M., and Saino, T.: Estimating of gas transfer velocity using triple isotopes of dissolved oxygen, J. Oceanogr., 66, 505-512, 2010.

Stanley, R. H. R., Jenkins, W. J., Lott, D. E. III, and Doney, S. C.: Noble gas constraints on air-sea gas exchange and bubble fluxes, J. Geophys. Res., 114, C11020, doi:10.1029/2009JC005396, 2009.

Stanley, R. H. R., Kirkpatrick, J. B., Cassar, N., Barnett, B. A., and Bender, M. L.: Net community production and gross primary production rates in the western equatorial Pacific, Global Biogeochem. Cy., 24, GB4001, doi:10.1029/2009gb003651, 2010.

Thiemens, M. H., Jackson, T., L., and Brenninkmeijer, C. A. M.: 
Observation of a mass-independent oxygen isotopic composition in terrestrial stratospheric $\mathrm{CO}_{2}$, the link to ozone chemistry, and the possible occurrence in the martian atmosphere, Geophys. Res. Lett., 22, 255-257, 1995.

Venkiteswaran, J. J., Schiff, S. L., and Wassenaar, L.: Aquatic Metabolism and Ecosystem Health Assessment Using Dissolved $\mathrm{O}_{2}$ Stable Isotope Diel Curves, Ecol. Appl., 18, 965-982, 2008.

Wieser, M. E. and Berglund, M.: Atomic weights of the elements 2007 (IUPAC Technical Report), Pure Appl. Chem., 81, 21312156, doi:10.1351/PAC-REP-09-08-03, 2009.

Young, E. D., Galy, A., and Nagahara, H.: Kinetic and equilibrium mass-dependent isotope fractionation laws in nature and their geochemical and cosmochemical significance, Geochim. Cosmochim. Ac., 66, 1095-1104, 2002.
Yung, Y. L., DeMore, W., and Pinto, J. P.: Isotopic exchange between carbon dioxide and ozone via $\mathrm{O}\left({ }^{1} D\right)$ in the stratosphere, Geophys. Res. Lett., 18, 13-16, 1991.

Yung, Y. L., Lee, A. Y. T., Irion, F. W., DeMore, W. B., and Wen, J.: Carbon dioxide in the atmosphere: Isotopic exchange with ozone and its use as a tracer in the middle atmosphere, J. Geophys. Res., 102, 10857-10866, 1997. 